\title{
Understanding Legal Understanding: The Legal Subject and the Problem of Legal Coherence
}

\author{
J.M. Balkin ${ }^{\dagger}$
}

\section{CONTENTS}

I. INTRODUCTION: A JURISPRUdENCE OF THE SUBJECT $\ldots \ldots \ldots \ldots \ldots \ldots$

II. Legal Coherence From the Standpoint of the Legal Object $\ldots \ldots \ldots 113$

A. The Different Meanings of Coherence . . . . . . . . . . 113

B. Legal Coherence as Consistency of Justification . . . . . . . . 115

C. The Dialectic of Hypothetical and Actual Justification ......... 117

III. LEGAL COHERENCE FROM THE STANDPOINT OF THE SOCIALLY

CONSTRUCTEd SUBJECT: COHERENCE AS RATIONAL RECONSTRUCTBBILITY . . 121

A. Rational Reconstruction as an Interpretive Attitude . . . . . . . . 123

B. The Dialectic of Rational Reconstruction and Rational Deconstruction .. 124

C. Rational Reconstruction and the "Internal Perspective" of Jurisprudence 127

D. The Production of Rational Reconstruction ............. 136

1. The Effects of Moral and Political Beliefs on Rational Reconstruction .................. 137

2. The Effects of Legal Knowledge on Rational Reconstruction . . . . . 137

3. Rational Reconstruction's Debt to Subjectivity . . . . . . . . . . 139

IV. Legal Coherence as Reduction of Cognitive Dissonance . . . . . 144

V. RATIONAL RECONSTRUCTION'S POWER OVER THE SELF . . . . . . . . 151

A. The Ontological Basis of Rational Reconstruction . . . . . . . . 151

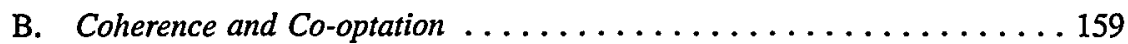

C. Legal Understanding as a Form of Power ............ 166

$\dagger$ Charles Tilford McCormick Professor of Law, University of Texas at Austin. My thanks to Bruce Ackerman, Akhil Amar, Sandy Levinson, Elizabeth Mertz, Dennis Patterson, Pierre Schlag, and Tom Seung for their comments on previous drafts, as well as to the participants at workshops at Yale Law School, the American Bar Foundation, University of Connecticut School of Law, and Western New England College of Law, where earlier versions of this Article were presented. 
VI. CONClusion: Politics, PERsonification, AND the

PRESERVATION OF INDIVIDUAL COHERENCE $\ldots \ldots \ldots \ldots \ldots \ldots$

\section{INTRODUCTION: A JURISPRUDENCE OF THE SUBJECT}

This is an essay about the law's coherence. It is also an essay about the various forms of legal understanding, the contributions that we make to these forms of understanding, and the effects that legal understanding has upon us. There is an intimate relation between these matters. Coherence is more than a property of law; it is the result of a particular way of thinking about the law. The experience of coherence is an activity of understanding; it is something we do with and to the law, and through this activity, we ourselves are changed.

The immediate purpose of this Article is to clarify the nature of legal coherence. But my larger purpose is to change the way we talk and think about jurisprudential problems. Along with a growing number of other legal scholars, I believe we must shift the focus of jurisprudence from the study of the properties the legal system is thought to have (for example, its coherence or determinacy) to the nature of the legal subject ${ }^{1}$ who apprehends the legal system and judges it to have these properties. ${ }^{2}$ In other words, to understand the nature of law, we must understand the nature of legal understanding.

1. A "subject" is a person who understands something; that something is the "object" of her understanding. Hence a "legal subject" is a person who attempts to understand the law, legal doctrine, and the legal system; these, in turn, are the "legal objects" she apprehends. Concern with the legal subject is thus a concern with how our processes of understanding affect and help constitute the cultural objects we comprehend. One might also use the term "legal subject" to describe how law or legal culture constructs how we think about people-how law and legal culture ascribe particular identities and features to people, defining some characteristics as salient and others as irrelevant. The "legal subject," in this sense, is a subject as seen (and dealt with) through the eyes of the law or legal culture.

2. Pierre Schlag has been at the forefront of this trend. In various ways, each of his writings has asked us to reflect on who does the thinking about law. See, e.g., Pierre Schlag, Fish v. Zapp: The Case of the Relatively Autonomous Self, 76 GEO. L.J. 37 (1987); Pierre Schlag, Normative and Nowhere to Go, 43 STAN. L. REv. 167 (1990); Pierre Schlag, Normativity and the Politics of Form, 139 U. PA. L. REV. 801 (1991) [hereinafter Schlag, Normativity and the Politics of Form]; Pierre Schlag, The Problem of the Subject, 69 TEX. L. REv. 1627 (1991) [hereinafter Schlag, The Problem of the Subject].

Other examples of the trend towards the study of the subject in recent jurisprudence include STANLEY FISH, DOING WhAT COMES NATURALlY: CHANGE, RHETORIC AND THE PRACTICE OF THEORY IN LITERARY AND LEGal STUdIES (1990); James Boyle, Is Subjectivity Possible? The Postmodern Subject in Legal Theory, 62 U. Colo. L. REv. 489 (1991); Rosemary J. Coombe, "Same As It Ever Was": Rethinking the Politics of Legal Interpretation, 34 MCGILL L.J. 603 (1989); Drucilla L. Cornell, Institutionalization of Meaning, Recollective Imagination and the Potential for Transformative Legal Interpretation, $136 \mathrm{U}$. PA. L. REV. 1135 (1988); Meir Dan-Cohen, Responsibility and the Boundaries of the Self, 105 HARV. L. REV. 959 (1992); Steven L. Winter, Indeterminacy and Incommensurability in Constitutional Law, 78 CAL. L. REV. 1441 (1990).

Critical Race Theory and Feminist literature raises the problem of subjectivity when it seeks to discover how perspectives of dominant groups are projected onto the social world so that they appear to be intrinsic features of that world. E.g., MARTHA MINOW, MAKING ALL THE DIFFERENCE (1990); PATRICLA J. WILLIAMS, THE ALCHEMY OF RACE AND RIGHTS (1991). Other examples of this scholarship argue that the subject's multiple allegiances resulting from her social situation create different and conflicting experiences of social reality, none of which can claim supremacy. See, e.g., Angela P. Harris, Race and Essentialism in Feminist Legal Theory, 42 STAN. L. REV. 581 (1990). 
Before discussing the specific problem of legal coherence, therefore, it is important to outline the general approach to jurisprudence employed in this Article, an approach that I think necessary if we are to take seriously law's interpretive character and its significance as a form of human culture.

I believe that we must transform the subject of jurisprudence into a jurisprudence of the subject-a jurisprudence that recognizes that questions about the nature of law must equally be concerned with the ideological, sociological, and psychological features of our understanding of the legal system. Thus, instead of asking whether the law has the property of coherence, we must begin by asking how judgments of coherence and incoherence come about. Instead of seeing legal coherence as a preexisting feature of an object apprehended by a subject, we should view legal understanding as something that the legal subject brings to the legal object she comprehends. Because the legal subject is herself socially constructed, we must consider how her social construction leads her to understand the legal system or its parts as possessing or lacking coherence. ${ }^{3}$ The goal of this approach is not to replace all inquiries about the legal object with those about the legal subject; it is rather to see the subject and object of legal interpretation as equal partners in the constitution of the legal system. We must pay greater attention to the legal subject now only because we have paid it so little attention before.

Expressions like "the legal subject" and "legal subjectivity" are potentially misleading because people often equate "subjectivity" with individuality and hence with individual idiosyncracies in belief and psychology. My interest, however, is in the sociological and ideological features of legal understanding - that which members of a culture share as well as that which differentiates them. Hence, I am concerned with "the subject" and "subjectivity" in a quite different sense. Surely each of us brings something distinctive to our experience of the social world. Yet any theory of ideology presumes that many individuals will share a great deal in their beliefs, attitudes, and modes of understanding. Thus, "subjectivity" involves an individual experience that results in part from internalization of cultural norms and shared frameworks of understanding. These cultural norms and frameworks are not simply superimposed on an individual's preexisting beliefs; they constitute her and form part of what makes her an individual. Subjectivity is what the individual subject brings to the act of understanding; it is what allows her to construct the object of her interpretation so that she can understand it. Yet what she brings may be quite similar to what others bring because of a shared ideology.

3. See Pierre Schlag, Contradiction and Denial, 87 MICH. L. REv. 1216 (1989) (reviewing MARK KELMAN, A GUIDE To CRITICAL LEGAL STUdiEs (1987)). This brief but insightful essay anticipates many of the themes of the present Article. 
I sometimes like to think of ideology as a sort of "cultural software"-a set of tools for understanding the social world, a copy of which is distributed to each of us. Our individual subjectivity employs and is constituted by this cultural software. If our copies are roughly similar-if we have internalized roughly the same cultural frameworks of understanding--then the contributions of each subject to the object of understanding will also be roughly similar. In this way, a shared subjectivity creates a shared objectivity. Hence, when I speak of "the legal subject" or the contributions of "subjectivity" I am invoking two complementary ideas: first, the individual's contribution through the act of understanding to her experience of the social world, and second, the individual's social construction, which helps shape the forms and bounds of her understanding. A jurisprudence of the subject is above all a cultural jurisprudence, for it is culture that creates legal subjects as subjects.

Thus, in emphasizing what the legal subject brings to the legal object, I am not arguing that features of the legal system like coherence or determinacy are "subjective" in the ordinary sense of that word, i.e., that they are merely in the eyes of the beholder who chooses to see the law in a particular way. The beholder is not fully in control of what she sees; she is part of a larger legal and political culture that shapes the very forms of her understanding. She does not choose the terms of her ideology or social construction. Rather she chooses through them; they form the framework within which her choices are understood and made.

Similarly, our inquiry into the contributions of "the legal subject" does not imply that the object of legal interpretation has no existence independent of a particular subject's comprehension of it. Our subjectivity contributes to, but does not create the cultural objects we comprehend. This is the dialectic between the subjective and objective aspects of social life-between individual thought, belief, and action on the one hand, and language, ideology, culture, conventions, and social institutions on the other. Culture and cultural objects have meaning only when they are understood by subjects, but their meaning is not dependent on the view of any particular subject. Language, ideology, culture, conventions, and social institutions construct and constitute the individual's subjectivity; yet language, ideology, culture, conventions, and social institutions exist only as instantiated in the thoughts, beliefs, and actions of individuals. ${ }^{4}$

In my view, the relative lack of interest in the legal subject in standard jurisprudential accounts is itself a sociological phenomenon worthy of study. Its key ideological feature is projection: the attribution of features of the self to the objects of understanding. ${ }^{5}$ When jurisprudential discussions neglect

4. For a more thorough discussion of this point, see J.M. Balkin, Ideology as Constraint, 43 STAN. L. REV. 1133 (1991) (book review).

5. For a discussion of ideological projection, see J.M. Balkin, The Mechanisms of Ideology: Bricolage and the Construction of Cultural Software (unpublished manuscript, on file with author); Schlag, The 
what the legal subject brings to the object of interpretation, they project the subject's contribution onto the object, thereby manifesting this contribution as a feature or property of law. ${ }^{6}$

This ideological projection has two consequences. First, it misdescribes the nature of the legal system, ignoring its necessary connections to human understanding. Second, and equally important, ideological projection makes the subject's contribution to the legal system invisible. It cuts off possible avenues of inquiry about the "we" who understand the law, thus shielding the subject from intellectual scrutiny. ${ }^{7}$

Indeed, the ideological concealment of the legal subject persists even in recent jurisprudential accounts that are eager to assert the fundamentally interpretive character of law. Consider, for example, Ronald Dworkin's wellknown theory of law as integrity. The strength of Dworkin's approach is its premise that legal understanding is an interpretive activity. ${ }^{8}$ Thus Dworkin asserts that individual subjectivity must play a significant role in the construction of features of the legal system. ${ }^{9}$ However, Dworkin has been unwilling to take this insight to its logical conclusion. If law is truly an interpretive enterprise, we must necessarily be concerned with the ideological, sociological, and psychological features of interpretation and their effects on our internal experience of understanding. This Dworkin has consistently refused to do. He has made clear that jurisprudential critique of a legal interpreter's views may not proceed on sociological, psychological, or ideological grounds. For Dworkin, these are "external" critiques, which can play no role in describing the nature of law..$^{10}$ The nature of law is determined by the internal perspective alone-the view of a subject making arguments within the legal system. ${ }^{11}$ Hence, one learns nothing about the

Problem of the Subject, supra note 2, at 1636; Schlag, supra note 3, at 1218; cf. WILliaMS, supra note 2, at 61 (attributions of criminality projected away from whites onto blacks, making white criminality invisible); Christine A. Littleton, Reconstructing Sexual Equality, 75 CAL. L. REV. 1279, 1310 (1987) (patriarchy locates difference in women rather than in social situations); Frances E. Olsen, The Family and the Market: A Study of Ideology and Legal Reform, 96 HARV. L. REV. 1497, 1570 (1983) ('The 'mystery' of sexuality consists in projecting human qualities separately onto males and females to make each the object of the other.").

6. Schlag, supra note 3, at 1218-19; Gary Peller, The Metaphysics of American Law, 73 CALIF. L. REV. 1151, 1154, 1289-90 (1985).

7. See Schlag, The Problem of the Subject, supra note 2, at 1633, 1729.

8. RONALD DWORKIN, LAW'S EMPIRE 87 (1986).

9. Id. at $87-90$.

10. According to Dworkin, "skepticism brought to an enterprise from the outside ... which engages no arguments of the sort the enterprise requires . . . can make no difference to our own efforts to understand and improve interpretation, art, and law." RONALD DWORKIN, A MATTER OF PRINCIPLE 177 (1985). Dworkin contends that this sort of "external" skepticism is either irrelevant or impossible. Id. at 176. Only "internal" skepticism is relevant to describing legal practice; this necessarily involves "arguments of the same contested character as the arguments it opposes." DwORKIN, supra note 8, at 85-86.

11. DWORKIN, supra note 8, at 85-86 (despite lawyers' demand for some form of objectivity beyond legal practice, they inevitably "return to their knitting-making, accepting, resisting, rejecting arguments in the normal way"; the "preliminary dance of skepticism" before returning to arguments within legal practice "is silly and wasteful"); see also DWORKIN, supra note 10, at 171 ("I have no arguments for the 
coherence of the legal system from understanding psychological or ideological needs to see law as coherent or incoherent. Rather, one must make claims about legal coherence and incoherence wholly within the terms of legal discourse by offering legal arguments for why a particular collection of doctrines or a particular justificatory scheme is coherent or incoherent. ${ }^{12}$

Thus, for Dworkin, the legal subject makes her appearance at the beginning of legal theory only to be shielded, protected, isolated, and forgotten thereafter. Once the legal subject has been installed as the interpreter and hence arbiter of the nature of law, psychological and ideological contributions to what she interprets are wholly beyond the bounds of jurisprudential scrutiny. All arguments must be directed instead to the nature of the object she constructs. In this way, Dworkin makes the subject who understands the law as coherent or incoherent invisible and impervious to psychological or ideological inquiry. Ironically, then, Dworkin, an early champion of the interpretive conception of law, has been among the most determined to exclude the legal subject as a subject of jurisprudential study.

Since H.L.A. Hart, jurisprudence has been grounded on the so-called "internal point of view"-the perspective of a participant in the legal system who regards its laws as norms for her behavior. ${ }^{13}$ In contrast, I believe that we must ground jurisprudence in a critical perspective, one that employs ideological critique to refiect on our internal experience of law. A critical perspective does not reject the importance of the internal perspective; on the contrary, it makes it a central object of analysis and scrutiny. It recognizes that this perspective constitutes law rather than simply mirrors it and acknowledges the plurality of its forms. A critical perspective takes seriously the contributions of subjectivity to the nature of law; it treats the sociology of knowledge as a full partner in the jurisprudential enterprise. Instead of taking for granted the primacy of the internal viewpoint of participants in the legal

objectivity of moral judgments except moral arguments, no arguments for the objectivity of interpretive judgments except interpretive arguments, and so forth.").

12. DworKIN, supra note 8 at 86 ; see also DwORKIN, supra note 10, at 174 ("I have yet been given no reason to think that any skeptical argument about morality can be other than a moral argument, or skeptical argument about law other than a legal argument, or skeptical argument about interpretation other than an interpretive argument."). Skeptical questions about a practice like law are always, in Dworkin's view, questions of interpretation which must be raised and posed within that practice. Id.

13. H.L.A. HART, THE CONCEPT OF LAW 86 (1961) [hereinafter HART, THE CONCEPT OF LAw]. Hart distinguished the internal perspective from an "external perspective," the point of view of an observer who sees legal rules not as norms that can be correctly or incorrectly followed but simply as producing regularities of behavior. Id. at 87 . Other scholars have noted that one does not have to feel bound by legal rules to understand them as norms, to grasp their point as directives, or to argue about what they require. See NeIL MACCORMICK, LEgal REASONING AND LEGAL THEORY 291 (1978); JOSEPH RAZ, ThE AUTHORITY OF LAW 153-54 (1979); JOSEPH RAZ, PRACTICAL REASON AND NORMS, 175-77 (1975). Hart has subsequently acknowledged that this constitutes a third, "hermeneutic" perspective. H.L.A. HART, ESSAYS IN JURISPRUDENCE AND PHILOSOPHY 14 (1983). Notwithstanding these qualifications, Joseph Raz has noted the general consensus among jurisprudential scholars of the centrality of the internal perspective to accounts of law. See Joseph Raz, The Relevance of Coherence, 72 B.U. L. REV. 273, 292 (1992) [hereinafter Raz, The Relevance of Coherence]. 
system, a critical perspective asks how this internal experience comes about. It recognizes in the internal experience of legal norms an effect whose causes must be unearthed and reflected upon.

To this end, we must recognize how deeply subjectivity affects all forms of legal understanding, not merely those in which we think that a particular individual misunderstands the legal system. It is tempting to describe legal misunderstanding in terms of something additional that a particular subject has brought to the act of comprehension - a certain baggage, whether of ideology or ignorance, that affects (and therefore distorts) the object she comprehends. Yet this characterization misunderstands the nature of misunderstanding because, ironically, it does not go far enough. It merely reinforces the ideological camouflage that makes subjectivity invisible in the ordinary case of legal understanding. Conceding that deviant forms of legal understanding may affect the construction of the object of understanding simultaneously treats these cases as exceptional to the normal, proper case of legal understanding, in which the subject does not intrude upon, distort, or affect the legal object but rather perceives the legal system as it really is. Drawing such distinctions obscures the legal subject's inevitable contribution to the world she understands. Hence, one arrives at jurisprudential projects that argue that they are concerned only with the nature of the law and not the types of mistakes that individuals might make about the legal system. In this way, the contribution of the subject who understands the legal system in the "correct" way is made invisible or irrelevant to jurisprudential inquiry.

In contrast, I insist that jurisprudence must consider how the legal subject constructs the object of her study even in those cases we consider normal or proper instances of legal understanding. The "normal" case of legal understanding is really a deviant case whose deviance has gone unnoticed, projected instead onto the object of legal understanding and given the name of legal reality. Legal understanding is a special case of legal misunderstanding: it is a "misunderstanding" appropriate for the purpose at hand. In both what we call legal understanding and what we assign to legal misunderstanding, the subject has already intruded and brought her fore-understandings, prejudgments, and psychological needs to bear. The subject is already part of the constructed object of interpretation; her invisibility is already reflected in the object's nature.

What difference will a critical or a cultural perspective make to the study of jurisprudence? What new light will be shed on jurisprudential questions by considering the legal subject's contribution to law? The jurisprudential approach I advocate transforms the answers to traditional questions and poses new ones. This Article argues that our subjectivity affects the process of legal understanding in three different ways that conventional jurisprudential discussions have either de-emphasized or ignored. 
First, subjects bring purposes to their understanding of law. The study of subjectivity is important to jurisprudence because we must recognize the different contributions we make to the object of understanding when we approach it for different purposes. Legal understanding is not simply the apprehension of preexisting properties of an object. It is a purposive activity of subjects. It is something that we do. ${ }^{14}$ To understand as a subject is to understand for a purpose, to participate in a social practice of understanding, and therefore to understand in a certain way that is driven by that purpose and that practice of understanding. We understand law for many different purposes, and we engage in many different activities that we unthinkingly lump together and call "understanding law."

Judgments of legal coherence result from one particular activity of understanding, an interpretive attitude I call rational reconstruction. This is an attempt to see the substantive reason that emanates from legal materials. However, rational reconstruction is not the sole or even the most important form of legal understanding. There are as many different kinds of legal understanding as there are purposes in understanding law. These different forms or activities of understanding are mutually interdependent, but they are not identical.

Jurisprudence has traditionally focused on a single "internal perspective" of participants in the legal system; it thus projects a particular interpretive stance onto the object of its contemplation and describes what it finds as "the nature of law." Nevertheless, because participants engage in a number of activities called "understanding law," the internal perspective is actually a multiple perspective. Instead of a privileged form of legal understanding that reveals the true nature of law, with all other forms of understanding parasitic upon it, I propose an alternative picture: a network of overlapping and interconnected forms of legal understanding, in which hierarchical status and relationships of dependence are provisional and much less clear. Focusing on the legal subject's contribution to legal understanding helps us to separate the various forms of legal understanding and grasp their mutual dependence and differentiation.

Second, subjectivity is important to understanding the nature of law because judgments of legal coherence and incoherence rest upon and are driven by features of the self. They are shaped by the features and sources of our understanding - our preexisting commitments, values, and beliefs, and our knowledge and ignorance of the legal system. Our experience of legal coherence is dynamic rather than static; it changes as we engage in cognitive work to understand legal doctrines and as we encounter new information and new experiences.

14. See PHILIP BOBbITT, CONSTTTUTIONAL INTERPRETATION 24 (1991). 
Because judgments of coherence and incoherence rest upon the nature of the self, they are also shaped by the self's psychological needs-in particular, by our need to make sense of the world and to see ourselves as rational, wellmeaning individuals. Understanding is always shaped by the self's need to preserve belief in its own coherence. Judgments of legal coherence and incoherence are affected by this need. In particular, the urge to reduce cognitive dissonance among our beliefs, actions, and commitments can cause us to see the law as coherent or incoherent. An approach that views coherence as a property of an object unaffected by our subjectivity will wholly miss these effects, for they will already have been projected onto the object of study. Thus we must recognize the contributions of subjectivity to understand how judgments of legal coherence and incoherence become a method of dissonance reduction for lawyers, legal academics, and even professors of jurisprudence.

Third, subjectivity is important to the study of law because legal understanding is also a source of power over the legal subject. In other words, if we want to understand legal understanding, we must recognize not only the effects that our understanding has on the objects we construct, but the effects that the act of understanding has on us. This feedback effect on the subject becomes invisible if we focus solely on the legal object. Jurisprudence usually envisions power only in political terms; it misses the power over the subject that arises from the act of understanding itself. Nevertheless, the process of making the law coherent, of rationally reconstructing it for ourselves, does not leave us untouched. Legal understanding is something that happens to us and changes us. It is a type of receptivity, of vulnerability, which affects us as much as it affects the law we attempt to understand. Legal understanding thus makes the legal subject a locus of ideological power, and the study of jurisprudence is and must properly be a study of this power. Yet the study of legal understanding must also be a humanist endeavor, in which we confront our human capacity for change-for better and for worse-through acts of understanding.

\section{LEgal COHERENCE FROM the StANDPOINT OF the LegAL OBJect}

\section{A. The Different Meanings of Coherence}

In this section, I introduce the problem of legal coherence. I argue that we cannot satisfactorily understand legal coherence solely as a property of a legal object independent of the contributions of the legal subject. If we try to think of coherence as a test that the law either meets or fails to meet, we will find that the criteria for this test are inherently unstable; as a result, many questions of legal coherence will prove to be essentially contestable and undecidable. Yet this does not mean that we do not and cannot experience the law as coherent. Rather, we must explain our experience of legal coherence in a different 
manner-we experience the law as coherent because we attempt to understand it in a certain way. This is the subject's contribution to legal understanding.

However, before we can begin our discussion of the specific form of understanding involved in judgments of legal coherence, we must first distinguish several different types of coherence. The first is the coherence of a set of factual beliefs, the second is the coherence of a normative system like the law, and the third is the coherence of the world around us. The coherence of factual beliefs is a question of logical or narrative coherence, while the coherence of the legal system is a question of normative coherence. The coherence of the world is prior to both: it is a feature of our existence as understanding beings and rests on our need to see ourselves as rational, morally sensitive people.

A collection of factual beliefs is logically coherent if the beliefs are logically consistent. A more stringent requirement of factual coherence is that the beliefs must be mutually supportive. An example of two mutually supportive beliefs is the belief that John owns a tennis racket and that John likes playing tennis; believing one tends to make the other belief more plausible and vice versa. However, when speaking of factual coherence, I shall, unless otherwise stated, employ the weaker requirement of logical coherence. A set of beliefs can be logically coherent even if they are not mutually supportive, as long as they do not involve a contradiction. In this sense, there is nothing incoherent (at least on the face of things) about believing both that John likes playing tennis and that Sarah is forty-three years old.

Sometimes we use "coherent" in a different and stronger sense to indicate narrative unity or unity of purpose; for example, an account of an event that introduced all sorts of irrelevant (but noncontradictory) facts might be said to lack coherence. This is a question not of logical but of narrative coherence. ${ }^{15}$ Thus, although a set of beliefs can be logically coherent in that they are noncontradictory, one can articulate them in a narratively incoherent fashion, so that the audience is confused or does not get the point of the account.

Normative coherence plays a considerable role in my argument; I shall describe it in greater detail momentarily. For now, we can say that normative coherence is the consistency not of logic but of principle. Values and normative judgments are normatively coherent if they employ distinctions and similarities that are principled and reasonable as opposed to those which are arbitrary and unreasonable. Judgments of normative coherence employ a substantive rather than a formal conception of reason. A substantive conception of reason is roughly captured by the statement that someone is acting "reasonably." A formal conception of reason is exemplified by first-order predicate logic. The more formal a conception of reason is, the more

15. See Bernard JACKSON, LaW, FACT, AND NARRATIVE CoherenCE (1990); MACCoRmick, supta note 13 , at $89-93$. 
indisputable its conclusions but the less relevant they are to practical judgment; the more substantive a conception of reason, the more relevant it is to practical judgment, but the more disputable its conclusions. ${ }^{16}$ Because normative coherence relies on a strongly substantive conception of reason, judgments of normative coherence are often contested and contestable.

The coherence of the world around us is special. It can include judgments of logical, narrative, and normative coherence, but it is of an entirely different order. The coherence of the world around us is demanded by our existence as understanding beings. Thus, it is not simply a feature of a particular set of beliefs; it is a feature of our beliefs. It is a goal of the activity of understanding, a global task in which we always engage.

There is a considerable difference between the coherence of a set of beliefs considered abstractly and the coherence of our own beliefs. We have a stake in the latter that we might not have in the former because we have a stake in our belief in ourselves as coherent, rational individuals. Considered in the abstract, the logical, narrative, or normative coherence of a set of beliefs has no personal implications for us. However, when the coherence of our own beliefs is called into question, the inquiry assumes an existential dimension: it becomes a question not about possible relations between abstract propositions, but about ourselves.

Thus, the coherence of the world is the coherence of our own beliefs about the world. If the world is not coherent to us, we must try to make it coherent in order to preserve our own sense of order about ourselves. This task may, in turn, require local judgments of logical, narrative, or normative incoherence. To make sense of the world as a whole, we may have to assume that a particular set of beliefs held by others is self-contradictory, that a particular person is acting arbitrarily, that particular legal doctrines are normatively incoherent, and so on. Hence, accounts of coherence in the social world, or in the actions and beliefs of others, are, at bottom, driven by our need to believe that our own beliefs are ordered, coherent, and rational. ${ }^{17}$

\section{B. Legal Coherence as Consistency of Justification}

What does coherence mean in the context of a legal system? I shall argue that, viewed as a property of a legal object, legal coherence is a type of normative coherence. It is a feature not of legal directives and existing legal materials but of the justifications we can offer for them. ${ }^{18}$ Hence, legal

16. A substantive conception of reason is also different from (and richer than) a purely instrumental conception of reason. Whereas the latter arbitrates only over the best means of achieving preexisting ends, the former arbitrates over both means and ends.

17. The connections between the preservation of the self and the coherence and incoherence of the law are discussed in Part IV infra, in connection with the theory of cognitive dissonance.

18. Raz points out that discussions of legal coherence necessarily assume a "base" of legal materials-legal decisions, statutes, rules, and regulations-that must be explained by various principles, 
coherence is the normative coherence of legal justification. The law (or a part of the law) is coherent if the principles, policies, and purposes that could justify it form a coherent set, which in turn means that all conflicts among them are resolved in a principled, reasonable, and nonarbitrary fashion. ${ }^{19}$

Stricter requirements of normative coherence are possible. For example, Joseph Raz has suggested that coherence requires unity of principle, so that the legal system would be most coherent if we could imagine it as emanating from a single principle. ${ }^{20}$ This is a very strong requirement of coherence, and one unlikely to be encountered in any significant part of the law. An alternative view, also suggested by Raz, would require the mutual interdependence of justificatory principles and policies. Just as our beliefs sometimes mutually support each other, the legal system would be coherent if it could be justified by a set of mutually interdependent principles and policies that stood or fell together. ${ }^{21}$ Although this requirement is weaker than the first, it is still too strict. It would be remarkable if the many different principles, policies, and purposes underlying the law stood or fell together. The justifications underlying the law are less interdependent than mutually competitive; our hope for a coherent legal system is that the law employs and arbitrates among them in a consistent and principled manner.

Neither of these stricter requirements captures the meaning of legal coherence..$^{22}$ Rather, coherence is the principled consistency of the principles and policies underlying the law. The law is coherent if we can view it as emanating from or as explainable by a set of consistent principles and policies. ${ }^{23}$ These principles and policies do not have to stem from a single

purposes, and policies. Raz, The Relevance of Coherence, supra note 13, at 284-85. This base is not completely fixed because the principles, purposes, and policies that explain the base may have a feedback effect that alters our judgment of what is properly considered to be in the base. Id. at 285-86. For example, the question of the proper extent of a particular doctrine or the proper interpretation of a statute or administrative regulation may be affected by our view of what principles, purposes, and policies best justify them. However, the base to be explained must exclude some things because otherwise it would not be clear that it was the law rather than something else whose normative coherence was at stake. Id. at 285 .

19. Cf. MACCORMICK, supra note 13, at 106 ("The basic idea is of the legal system as a consistent and coherent body of norms whose observance secures certain valued goals which can intelligibly be pursued all together."). MacCormick's view, like my own, is driven by conceptions of reason and reasonableness that are essentially substantive and practical, but for this reason are also inevitably contested. Id. at 266-74.

20. See Raz, The Relevance of Coherence, supra note 13 , at 286 . Raz calls justification by a single principle "strong monistic coherence." Id. Although he offers alternative definitions of coherence, his basic criterion is that the more unified the principles which explain the law, the more coherent the law is. Id.

21. Id.

22. Because the law seems to contain many different principles, policies, and purposes, it is not very difficult for Raz to conclude that the law is not coherent under his definition of coherence. See id. at 295, 310-14. Indeed, because his criteria are so exacting, he concludes that Dworkin's theory of "Iaw as integrity" in Law's Empire is not really a coherence theory at all. See id. at 315-17 (noting that although Dworkin uses the word coherence, his theory of integrity does not require monistic coherence or mutually dependent principles). Although I find Raz's definition too restrictive, much that he says about legal coherence in his sense can be applied to broader conceptions of legal coherence, see id. at 296-97, and I shall try to note the relevance of his arguments to mine as the occasion arises.

23. Dworkin distinguishes between principles and policies. See RONALD DwORKIN, TAKING RIGHTS 
master principle or policy, nor do they have to be mutually interdependent so that if one goes they all go. Nevertheless, they must be mutually supportive to the extent that they are consistent with each other, and any potential conflicts among them must be resolved in a consistent and principled manner.

Note that judgments of coherence can be local or global; they can be about individual doctrines, entire bodies of law, or the legal system as a whole. ${ }^{24}$ We can say that the law of owner-occupier liability is coherent but not the law of respondeat superior, for example. If a part of the law is incoherent, then it may make a larger part of the law that includes it incoherent as well, because it produces unresolved conflicts with other parts. Moreover, even if two parts of the law seem coherent in isolation, they might be normatively incoherent when taken together. It is therefore possible that one could see the law as being normatively coherent locally everywhere and yet it would not necessarily follow that the law as a whole was coherent.

\section{The Dialectic of Hypothetical and Actual Justification}

Viewed as a test or a requirement that the law must fulfill, legal coherence involves the consistent use of principles and policies to justify legal doctrine. However, we have said nothing as yet about the content of these principles and policies. There are two contrasting positions we could take:

(1) The law (or some part of the law) is coherent if we can explain it by a set of consistent principles and policies which, if they were justified, would justify the content of legal doctrine (which may include constitutional, statutory, administrative, and decisional law).

(2) The law (or some part of the law) is coherent if we can explain it by a set of consistent and justified principles and policies which, taken together, justify the content of legal doctrine. ${ }^{25}$

SERIOUSLY 90-100, 113-15, 294-327 (7th prtg. 1980) [hereinafter DWORKIN, TAKING RIGHTS SERIOUSLY]; DwORKIN, supra note 8, at 221-24, 243-44. In his view, the former, but not the latter, are primarily relevant to determining the coherence of the legal system, despite the fact that policies play some role in proper interpretation of statutes. See DWORKIN, TAKING RIGHTS SERIOUSLY, at 107-10; DWORKIN, supra note 8, at $313 \mathrm{n} .1,338-39$. In contrast, I shall assume that a defender of legal coherence may employ both in offering a coherent account of legal materials. Cf. MACCORMICK, supra note 13, at 259-64 (rejecting distinction for purposes of determinations of legal coherence).

24. See Barbara B. Levenbook, The Role of Coherence in Legal Reasoning, 3 LAW \& PHIL. 355, 371 (1984) (arguing that law is only locally coherent); Raz, The Relevance of Coherence, supra note 13, at 31114 (same).

25. Cf. Raz, The Relevance of Coherence, supra note 13, at 290 (modifications of law as coherence thesis). Note that the "consistency" referred to in both definitions is the consistency of principle. Principles and policies must be applied in a consistent manner and all conficts among competing principles and policies must be resolved in a principled manner. Even if one could articulate a set of principles and policies that explained existing law, the law would not be coherent if these principles and policies were not applied-and potential conflicts between them were not resolved-in a consistent, principled fashion. As a result, in both definitions, the relevant set of principles and policies must include principles and policies used to arbitrate between competing principles and policies and to ensure the consistency of their application. 
These two positions differ in an important respect. The first says that the law is coherent if there is a set of consistent principles and policies that explains legal doctrine, even if we do not agree with these principles and policies. The second says that the principles and policies that explain existing law must themselves be morally justified. Let us call the first the requirement of hypothetical justification and the second the requirement of actual justification. Obviously, actual justification is a more stringent test of coherence.

A test of actual justification has important disadvantages. Most people who defend the coherence of the law against critical attack would not assume that belief in legal coherence commits them to the view that the law is fully morally justified or that existing legal doctrines cannot be to some extent unjust or oppressive. The question of legal coherence seems to be about something more (or rather something less) than the question of justice. To be sure, one of the reasons we are concerned with legal coherence is that we believe that it has effects on justice. However, this does not mean that coherence and justice amount to the same thing. Procedural fairness also contributes to justice, but it is not the same thing as justice; if substantively evil laws are applied with procedural fairness, they can still lead to very unjust results. In the same way, the requirement of coherence seems to be less demanding than full moral justification.

In contrast, the test of hypothetical justification does preserve the distinction between a coherent legal system and an ultimately just one. It requires only a consistent set of moral principles which, if they were justified, would justify existing legal doctrine. Nevertheless, this theory of legal coherence has complementary difficulties. If the test of actual justification is too stringent, the test of hypothetical justification is too forgiving; it makes the standard of coherence too easy to meet. Because the norms that justify the law do not themselves have to be justified, one could simply make up a series of principles and policies that match the categories and distinctions already present in the law. Thus, if the law denies recovery for economic loss in tort, it can be justified by the moral principle that economic loss should not be recovered in tort. Like a map describing a country on a 1:1 scale, which would be so accurate as to be useless, a coherence account that exactly matches the content of existing doctrine does no justificatory work. It gives us no explanation for why coherence (in the sense of hypothetical justification) is an important or valuable feature for a legal system to have; at the very least it does not serve the goal of justifying the coercive power of the state through law. ${ }^{26}$ The test of hypothetical justification proves to be no test at all, for there will almost always be some set of logically consistent principles and

26. See MACCORMICK, supra note 13 , at 106-07 (emphasizing that need for coherence explains and justifies judicial role). 
policies, no matter how substantively arbitrary or insane, that explains existing legal doctrine.

We thus find ourselves on the horns of a dilemma. A theory of actual justification too readily collapses questions of coherence into those of moral justification and thus guarantees that almost any existing legal system will lack coherence. On the other hand, a principle of hypothetical justification, by divorcing questions of coherence from those of moral justification, seems to do no important justificatory work at all; it threatens to make the issue of coherence tautological.

Considered as a property of a legal object, legal coherence must lie somewhere between the minimal requirements of hypothetical justification and the maximal requirements of actual justification. If any normative principle could serve as a moral principle for purposes of hypothetical justification, hypothetical justification would impose no restraints on the content of legal norms. Hence, there must be some limits on what qualifies as a justificatory principle or policy in an account of legal coherence. ${ }^{27}$ Legal coherence must be hypothetical justification according to a particular type of moral principle or policy. For purposes of this discussion, let us call these "bona fide principles and policies." Then we might say that a legal system was coherent if it were hypothetically justified by bona fide principles and policies, and if all conflicts among these principles and policies were in turn resolved through consistent application of bona fide principles and policies.

Merely to state the matter in this way suggests the inherent contestability of questions of legal coherence. Thus, people will disagree over whether a certain principle or policy is bona fide; they will disagree about the proper extension or scope of a bona fide principle or policy; and lastly, they will disagree about whether conflicts between competing policies and principles have themselves been resolved in a principled manner-that is, according to bona fide principles and policies. Indeed, the latter may be the most important form of disagreement in practice. Although people often can agree that certain abstract principles and policies are important, they will often disagree about the consistency of their application and the principled resolution of conflicts between competing principles.

In these disagreements and debates, questions of actual justification necessarily resurface. How does one decide that a policy or principle can form part of a scheme of hypothetical justification or that the balance between competing principles or policies has been properly struck? Although legal coherence does not require that the principles underlying the law be actually justified, questions of moral justification must play an important role in determining the limits of what can constitute a bona fide principle or policy, the proper scope of such principles and policies, and how conflicts among

27. See Levenbook, supra note 24 , at 357-58. 
them are to be resolved. Legal coherence always implicates questions of actual justification even though it is not identical with actual justification. ${ }^{28}$

The relationship between bona fide principles and actual justification explains why the test of legal coherence must be more than mere intelligibility or logical consistency, standards that apply to the coherence of a set of factual beliefs or propositions. Factual beliefs are coherent if they are logically consistent or "hang together." The coherence of normative justification differs because of the nature of the subject matter that has to "hang together." There are no formal constraints on the kinds of factual beliefs that can form a coherent set, so long as they are logically consistent. However, not everything can count as a bona fide principle or policy; hence, mere intelligibility or logical consistency cannot be the test of coherence in law. If we cannot see the law as the product of bona fide moral principles and policies, we do not even reach the question of consistency between them.

In arguing that legal coherence is necessarily dependent on questions of actual justification, I am not claiming that questions of coherence must ultimately collapse into those of actual justification so that a legal system cannot be coherent unless it is actually justified. Rather, I am making two interrelated points. First, actual justification is essential to legal coherence because it polices the boundaries of the kinds of principles and policies that

28. Consider, for example, the following two principles, taken from a discussion of tort law in Dworkin's Law's Empire: (1) "No one has a moral right to compensation except for physical injury," and (2) "People have a moral right to compensation for emotional injury suffered at the scene of an accident against anyone whose carelessness caused the accident but have no right to compensation for emotional injury suffered later." DwORKIN, supra note 8, at 240 . Dworkin easily rejects the first as a justificatory principle because it does not fit existing cases. Id. at 242. However, he rejects the second on the grounds that "it does not state a principle of justice at all." Id. Stated in terms of our previous discussion, Dworkin is saying that the second statement cannot serve as a principle for purposes of hypothetical justification. A system of norms that included it would fail the test of hypothetical justification and would not establish the coherence of the legal system.

Nevertheless, one might ask why the first principle could possibly constitute a principle of justice while the second cannot. My view is that the exclusion of such principles from a coherent scheme of legal justification cannot be on grounds of logical form. It must be on the grounds that the distinctions and similarities drawn by these principles are morally arbitrary. See id. (arguing that the second principle "draws a line that it leaves arbitrary and unconnected to any more general moral or political consideration."). In other words, it must be on the grounds that Dworkin believes these principles fail the test of actual justification.

A similar point applies to resolution of conflicts between principles or policies. There are many ways that we can arbitrate between various principles and policies in a logically consistent manner, and not all of them deserve the title of coherent reconciliations. For example, consider two principles in tort law, the principle that liability should be proportionate to fault, and the principle that persons who have been harmed by the actions of others deserve compensation. Sometimes these principles point in the same direction, but sometimes they conflict, and then we must choose between them. Suppose that we decide that we will resolve the conflict in favor of the fault principle when the plaintiff is less than six feet tall, and in favor of the compensation principle when the plaintiff is six feet or taller. Although there is nothing logically inconsistent about this resolution of the conflict, it seems morally arbitrary. Put another way, conflicts among principles or policies must be resolved by principle, and not by logically consistent but morally arbitrary distinctions and assignments. In deciding how to reconcile competing principles or policies in legal doctrine, we expect that our reconciliation will itself be principled. Thus, when we complain about the reconciliation of two competing principles, we are not complaining about a logical contradiction between them, but about a failure of adequate moral justification for the distinctions drawn and the balances struck. 
"hang together" in a coherent scheme of legal justification. Second, one can only attack the normative coherence of the legal system through arguments about actual justification. We demonstrate legal incoherence by demonstrating the moral arbitrariness and unreasonableness of the justifications offered for legal doctrines. That is why debates about legal coherence are inevitably linked to debates about actual justification.

Nevertheless, although lack of actual justification is a necessary condition for rejecting a proposed justification of legal doctrine, it is not a sufficient condition. What is a sufficient condition? It is the test of a bona fide principle or policy. It is the question of whether or not a principle or policy is so arbitrary or unjust that we must exclude it from a scheme of hypothetical justification. However, there can be no definitive answer to this question, and therefore the question of legal coherence (defined as hypothetical justification by bona fide principles and policies) is essentially contested and contestable. Thus, instead of a unified theory of legal coherence, we have an endless dialectic between the principles of hypothetical and actual justification in which one side defends the consistency of legal doctrine while the other attacks it on the grounds that it is unjust, unreasonable, and arbitrary. Because of the dialectic of hypothetical and actual justification, it is always possible to attack a scheme of hypothetical justification on the grounds that it employs principles or policies that are arbitrary or unjust, or that it arbitrates between competing principles or policies in an arbitrary or unjust fashion. This attack may be unsuccessful or unpersuasive in a particular case; however, it cannot be rejected merely on the grounds that legal doctrines do not need to be just to be coherent. Rather, one must respond that even though legal doctrines are not ultimately just, they are reasonable. Yet the grounds for this judgment of reasonableness depend heavily on beliefs about actual justification. As a result, people may disagree about the coherence of the legal system because of their different views about justice, morality, and politics, even though the test of legal coherence is not one of actual justification.

\section{LEGAL COHERENCE FROM THE STANDPOINT OF THE SOCIALLY CONSTRUCTED SUBJECT: COHERENCE AS RATIONAL RECONSTRUCTIBILITY}

The tests of hypothetical and actual justification envision legal coherence as a feature of an object. The law is coherent if it has certain properties; it has these if it passes a certain test. As we have seen, this approach results in an undecidable dialectic between the requirements of hypothetical and actual justification.

Now we must consider the problem from a different angle. Instead of asking what properties the legal object must have in order to be coherent, we must consider what has to be true of a legal subject in order for the law to be coherent to her. What do legal subjects do when they form judgments of legal 
coherence and incoherence? What do they bring to the task of legal understanding? What characteristics of subjectivity produce their judgments of legal coherence? Of what features of their thought are judgments of legal coherence the result?

Judgments of legal coherence arise when we understand the law in a particular way. I call this special type of legal understanding rational reconstruction. As explained more fully below, rational reconstruction is the attempt to see reason in legal materials-to view legal materials as a plausible and sensible scheme of human regulation. The experience of legal coherence is the result of our attempt to understand law through the process of rational reconstruction.

Some authors use the term "rational reconstruction" as a test of legal coherence; the law is coherent if it is amenable to rational reconstruction. ${ }^{29}$ I do not use the term in this way because this conceals the subject's contribution to legal judgment. Rational reconstruction is not simply a test for properties of or relations between legal norms. It is a way of looking at law. ${ }^{30}$ To say that law is amenable to rational reconstruction is to make a claim about both an object and a subject who constructs the object in a particular way so that she may understand it. The law is rationally reconstructible when a legal subject views the law for a certain purpose with a certain result. Implicit in this view is the possibility that she might view the law for a different purpose, or under different circumstances, with a correspondingly different result.

The question of legal coherence is ultimately the question of the conditions of rational reconstructibility. This is a study not only of features of the law, but of how subjects construct the law they understand. Thus, to understand legal coherence we need to ask the following questions:

(1) What is involved in the specific form of understanding called rational reconstruction?

(2) How does this form of understanding differ from other forms of legal understanding?

(3) What features of our experience affect the process of rational reconstruction and hence our judgments about legal coherence?

(4) What effect does the process of rational reconstruction have upon us?

The remainder of the Article will be concerned with these questions.

29. E.g., ANDrew Altman, Critical Legal, Studies: A Liberal Critique 117-18, 121-23, 127 (1990) (viewing CLS arguments as claims that law is not rationally reconstructible; doctrine is rationally reconstructible if it may be seen as conceptually derivable from a single coherent ethical view); Neil MacCormick, Reconstruction after Deconstruction: A Response to CLS, 10 OXFORD J. LEGAL STUD. 539 (1990) (offering rational reconstruction as alternative to CLS accounts of law).

30. MacCormick speaks helpfully of rational reconstruction as an activity, and this approaches my use of the term. MacCormick, supra note 29, at 556 (describing rational reconstruction as "the production of clear and systematic statements of legal doctrine, accounting for statute law and case law in terms of organizing principles"). The difficulty is that MacCormick is still concerned with the activity of organizing a legal object, and not with the subject who engages in the activity. 


\section{A. Rational Reconstruction as an Interpretive Attitude}

Rational reconstruction is the attempt to see parts of the law as a defensible scheme of principles and policies. We rationally reconstruct a part of the law when we seek to apply it to a concrete case. To apply legal rules we must attempt to understand their point, and this requires us to imagine reasonable principles and policies underlying legal doctrines. We need not agree with these principles and policies in all respects; our concern is that they seem consistent and reasonable to us. In considering what is reasonable, we use something more than the principle of non-contradiction; we employ a substantive conception of reason. ${ }^{31}$ To rationally reconstruct the law is to attempt to understand the substantive rationality emanating from it.

Consider the common-law doctrines of owner-occupier liability. These doctrines distinguish among the duties that an owner-occupier owes to trespassers, social-guest licensees, and business invitees. We can have many different interpretive attitudes towards these doctrinal distinctions. For example, we can criticize their justice or view them as historical artifacts. We rationally reconstruct these doctrines when we try to understand their point so that we can apply them. We try to imagine the policies and principles that might explain these doctrines and how a reasonable and morally sensitive individual might believe that the doctrines employ sound distinctions. Thus, rational reconstruction is not merely a criterion or test; it is also a purpose for interpreting and an attitude expressed towards the object of interpretation. The attempt to see the point of doctrines, the attempt to envision ourselves as sympathetic advocates for these doctrines so that we can apply them, is the hallmark of the interpretive attitude I call rational reconstruction.

We might rationally reconstruct these doctrines as follows: When people use their land for business purposes, or for the hope of some economic benefit, they should be held to an ordinary standard of due care. However, when they allow others to come onto their property without expectation of economic benefit, or when they invite people onto property that is not generally held open to the public (for example, when they are merely having their friends over for dinner), they should have less stringent obligations. Finally, when a

31. Thus, when we say that a person is being unreasonable, we do not mean that she is guilty of a logical contradiction, for there is almost always some logically consistent set of beliefs, no matter how farfetched, that could support her views. What we mean is that we doubt the reasonableness of her beliefs. Conversely, our view that a person is being reasonable is not a comment on the logical consistency of her beliefs but a judgment that her beliefs are reasonable in a substantive sense. Formal rationality is indisputable but empty-it tells us little about the world of facts or the world of values; substantive rationality is full of content but controversial, so that people often may disagree about what is reasonable or unreasonable from this standpoint. In his treatment of legal reasoning, Neil MacCormick has also stressed the substantive and disputable nature of the rationality that we use in forming legal judgments. See MACCORMICK, supra note 13, at 5, 265-74. 
person invades their land without their permission, they should have the lowest duty of all.

We might believe that these distinctions are unjust and that the law should not make them. Yet the goal of rational reconstruction is not to offer our own account of how doctrine should be constructed. It is to bring a charitable attitude towards the legal object and to envision how it could be a reasonable accommodation of principles and policies that are themselves reasonable. It is to see how the application of these doctrines to concrete situations makes sense..$^{32}$ If we find ourselves able to provide such an account, we can say that the law is rationally reconstructible even though it does not fully comport with our ideas of justice. ${ }^{33}$ When we can successfully take this attitude towards the law of owner-occupier liability, we will say that this body of doctrine is coherent.

I do not mean to make too much of the simple account of owner-occupier liability just proposed. I do not mean to suggest that this is the only account or even the best account that could be given of these doctrines, much less that everyone would agree that $I$ have provided a substantively reasonable account. Indeed, my argument about the nature of legal coherence assumes that some people will disagree and assert that I have not offered a successful rational reconstruction. I am merely suggesting that when we understand law in order to apply it, we bring an attitude of charity towards the law and that in this task we can and do offer principles and policies, grounds of distinction and grounds of similarity, that seem intelligible, workable, and reasonable, even if we are not wholly convinced that they are morally best. The rational reconstruction of law rests on the possibility of taking this attitude and being able to offer such accounts.

\section{B. The Dialectic of Rational Reconstruction and Rational Deconstruction}

Nevertheless, rational reconstruction is only one interpretive attitude we take towards the law. There is another, equally important way of understanding the legal system-an attitude I call rational deconstruction. We rationally deconstruct the law when we critically examine legal doctrine to discover its shortcomings. We do not bring the charitable attitude of rational reconstruction to the object of our interpretation. Our goal is not to see the law's substantive rationality, but its failures in that regard. ${ }^{34}$

32. This point is discussed in more detail infra Part V.A.

33. However, our views of what is just may be affected by this encounter. See the discussion of hermeneutic co-optation infra Part V.B.

34. Hence I call this interpretive attitude "rational deconstruction" and not simply "deconstruction" because it is grounded in a judgment of substantive rationality. One could engage in deconstruction of a legal text without the desire to offer a normative alternative, or without a belief that the difficulties one found in the text were due to failures of substantive rationality. See, e.g., Pierre Schlag, Le Hors' de Text, C'est Moi: The Politics of Form and the Domestication of Deconstruction, 11 CARDOZO L. REV. 1631 
Consider our rational reconstruction of owner-occupier liability. We might criticize this account in the following way: It makes no sense for the defendant's duty to exercise due care to depend on the plaintiff's status as trespasser, licensee, or invitee. Absence of an expectation of economic benefit to defendants does not justify limiting the duty to licensees and trespassers. After all, we hold defendants liable for failure to exercise due care in automobile accidents even if they have no economic relationship to their victims or are complete strangers. Similarly, the fact that the plaintiff is a wrongdoer does not eliminate the defendant's duty to exercise due care in automobile accidents unless the plaintiff's wrongdoing is the proximate cause of her injury, so that it was foreseeable from the nature of the plaintiff's conduct that she would be injured. This cannot be said of all cases of trespassing. Hence, we might argue, the doctrines of owner-occupier liability are unprincipled because they draw arbitrary distinctions between individuals and situations. They are not rationally reconstructible and therefore are not normatively coherent. ${ }^{35}$

Just as rational reconstruction involves an attempt to see the substantive rationality emanating from the law, rational deconstruction attempts to recognize how law has failed to live up to the standards of substantive rationality. Rational deconstruction attacks what rational reconstruction defends. To critique a set of doctrines as unprincipled is to critique a proposed rational reconstruction of them; hence, rational deconstruction seeks to show that candidates for rational reconstruction of an area of law are unsatisfactory.

Rational deconstruction of doctrine operates through an appeal to other principles or policies, either implicit or explicit. When we say that a proposed reconstruction of doctrine fails, we are not making a claim about logical contradiction. We are claiming that legal distinctions and similarities have not been adequately justified. When we say that the explanations are not reasonable, we really appeal to standards of justice and sound policy. We appeal to distinctions that would be just, similarities that would be sound. Once again, although coherence and actual justification are not identical, the only way that we can demonstrate incoherence is by an appeal to standards of actual justification. Rational deconstruction makes an argument about a failure of substantive rationality that must employ its own conception of substantive rationality; it offers an argument about justice that invokes its own conceptions of what could be just.

(1990) (criticizing normative uses of deconstruction). However, the deconstruction practiced by legal critics is almost always rational deconstruction, because it seeks to criticize law on the basis of some proposed normative alternative.

35. Note that this particular rational deconstruction operates by expanding the scope of legal doctrine being compared. It demonstrates conflicts within a specific area of law by suggesting that they are inconsistent with other areas of law. Nevertheless, rational reconstruction need not always be comparatively local and rational deconstruction need not always operate by global comparisons. 
In this way the interpretive stances of rational reconstruction and rational deconstruction employ the dialectic between hypothetical and actual justification. Rational reconstruction constructs a scheme of hypothetical justification by bona fide principles and policies, which is more than logical consistency but less than actual justification; rational deconstruction denies hypothetical justification but proceeds through an attack based on actual justification.

It is important not to confuse these two dialectics. Actual and hypothetical justification are criteria for judging whether legal doctrines are coherent or incoherent. They are tests that an object of interpretation has to meet in order to say that a certain property (coherence) is true of it. In contrast, rational reconstruction and rational deconstruction are interpretive attitudes we have about the legal system; they are the ways in which we look at legal doctrines, which in turn give rise to judgments of coherence and incoherence. The dialectic of actual and hypothetical justification means that we alternate between criteria for legal judgment. The dialectic of rational reconstruction and rational deconstruction means that we alternate between ways of looking at the legal system-sometimes as the repository of a coherent substantive rationality and sometimes as a jumble of conflicting principles and policies.

Although I have described these two interpretive stances as separate, they actually depend upon each other. Rational reconstruction of legal doctrine requires the tools of rational deconstruction in two senses. First, many different accounts of legal doctrine are logically consistent, but not all of them involve morally satisfying principles and policies. Therefore, in constructing a rational reconstruction of doctrine, we must have some way of choosing among the different accounts of the principles and policies that could be said to emanate from existing legal doctrines. Our tool for sorting and judging is rational deconstruction. We reject explanations of legal materials if they seem unprincipled or morally unsatisfying. Rational deconstruction resembles the sculptor's tools that allow her to uncover the statue buried in a block of marble. The sculptor constructs a work of art, but she must do so by eliminating what is inconsistent with her artistic vision. To create she must eliminate; to construct, she must deconstruct. So too the rational reconstructor only achieves her goal by the use of rational deconstruction.

Second, when we rationally reconstruct the law, we often find that we must classify certain legal materials (for example, certain judicial decisions) as anomalies. Even when we judge the law as rationally reconstructible according to a certain story, we will discover that certain parts of it do not fit that story. So we may acknowledge that part of the existing corpus of legal materials are exceptions, mistakes, or wrongly decided cases. Hence, we have two decisions to make: first, whether there are anomalies, and second, which part of the existing legal materials will be considered the anomaly and which part the "real" or "correct" portion of the law that conforms to our story. 
Different stories will assign these roles to different parts of the legal corpus. Our belief in the rational reconstruction of the law requires us to show that anomalies are exceptional elements of an otherwise coherent whole, elements that could be excised without doing irreparable damage to the fabric of the law. If anomalies are like warts that detract from the beauty of a face, different stories about law may make the same decision a wart or a beauty mark. Indeed, what seemed to be a wart in one story might under another be a central feature of the face. Our belief in the rational reconstruction of the law requires us to show that anomalies are indeed anomalous-that they are like a wart as opposed to a nose. Thus our rational reconstruction—our story of the principles and policies behind the law-must purport to tell us what is central and what is peripheral in legal doctrine.

In order to tell what is anomalous and what is central to our story, we need the tools of rational deconstruction. Through rational deconstruction we decide that two parts of the existing corpus cannot live together in a coherent scheme of principles and policies and that we must choose between them. Rational reconstruction thus makes use of rational deconstruction not only in determining which consistent sets of principles and policies could serve as a rational reconstruction, but also in deciding which parts of the legal corpus must be explained by the rational reconstruction and which parts can be jettisoned as mistaken. There is no rational reconstruction, in other words, without rational deconstruction, just as there is no cup without the void it encloses, and no statue without the space that surrounds it.

If the task of rational reconstruction depends on the prior use of rational deconstruction, the reverse is also true: all rational deconstruction depends on some alternative successful rational reconstruction of existing doctrinal distinctions and similarities, or upon a set of distinctions and similarities that do not presently exist in law but that could exist in a law that is yet to be. To accuse legal doctrine of incoherence is to imagine a set of legal doctrines that might be coherent; to assert that explanations of existing doctrine are not reasonable is to appeal to distinctions and similarities that could be reasonable. If rational reconstruction achieves its aims by rational deconstruction, rational deconstruction lives off the hope of a future rational reconstruction to which the sorry present might aspire.

\section{Rational Reconstruction and the "Internal Perspective" of Jurisprudence}

Perhaps the most important thing one can say about rational reconstruction is that it is not the only form of legal understanding. It is not even the most central or most important form of legal understanding. We have already seen its mutual dependence upon another form of legal understanding, rational deconstruction. Nor do these two forms of legal understanding exhaust the possibilities. Understanding is a purposive activity. Because there are many 
different purposes in understanding the law, there can also be many different forms of legal understanding. In order to study the subject's contribution to legal understanding, we must recognize the many different purposes behind legal understanding, as well as the social roles, activities, and contexts that give rise to these purposes. To understand law, we must ask who seeks to understand the legal system and why they seek to understand it.

These distinctions are not always clearly made in current jurisprudential writing. In his discussion of legal coherence, for example, Joseph Raz assumes that coherence is a property of law revealed through the preferred perspective of orthodox jurisprudence, the "internal point of view." It is irrelevant that the law lacks coherence from any other perspective. "Given the admitted priority of the participant's point of view," Raz argues, "even the [outside] observer, in order to acquire a sound understanding of the law, must understand it as it would be seen by a participant. If it must be coherent to a participant then coherent it is." 36

The difficulties here are twofold. First, there are many different types of "participants": laypeople and professional elites, for example. Within the category of professional elites there are litigators, judges, bureaucrats, academics, and so on. Thus, there can be more than one "internal perspective" because there are many different social groups who regard legal rules as norms for conduct. If these different groups disagree about their perceptions of legal coherence, their disagreements must be resolved in some fashion. ${ }^{37}$

Second, within each group of participants there are many different purposes for understanding the legal system, such as predicting what other legal officials will do, arguing for legal reform, or understanding the practical effects of legal norms. These forms of understanding raise the issue of coherence in different ways, and for some of them coherence may even be irrelevant. Thus, there can be more than one "internal perspective," because people who regard legal rules as norms for conduct can have more than one purpose in understanding law.

Consider five different purposes for understanding the law. First, we may wish merely to make sense of the law as a coherent scheme of regulation in order to learn it or apply it. Second, we may want to predict what other legal actors will do. Third, we may wish to describe the law in order to persuade

36. Raz, The Relevance of Coherence, supra note 13, at 293 (emphasis added).

37. Although Raz does not specifically address the point, I assume that he, like most other jurisprudence scholars, would generally resolve such dispures in favor of the perspective of elites. For example, Hart argued that for a legal system to exist it is only necessary that authoritative legal officials hold the internal perspective. See HART, THE CONCEPT OF LAW, supra note 13, at 113-14. How conflicts between judgments by different elites (for example, litigators and judges, or judges and academics) should be resolved is quite another matter. I suggest that jurisprudence has rarely emphasized the possibility of such conflicts within elites, assuming instead that the standard of the judge is paradigmatic and that of the litigator, executive official, legislator, or academic is parasitic on this perspective. For a similar criticism, See ROGER COTTERRELL, THE POLITICS OF JURISPRUDENCE 230 (1989). 
others to interpret the law in our favor. Fourth, we may offer a critical portrait of existing law in the hope of persuading others to change the law. Fifth, we may wish to understand law in terms of its practical effects rather than in terms of the content of its doctrines. Professional elites adopt all of these purposes in understanding law; laypeople adopt some or all of them. Moreover, this list is not intended to be exhaustive; there are doubtless other purposes in legal understanding as well. The point is that "understanding law" encompasses many activities. In each of these activities we approach the law in different ways.

When we seek to make sense of the law in order to learn or apply it, we employ rational reconstruction. Yet rational reconstruction cannot serve all of the other purposes of legal understanding. For example, it does not always accurately predict the behavior of legal officials, and it cannot tell us the practical effects of legal norms.

Furthermore, although rational reconstruction asks us to attempt to see the law as a coherent scheme of regulation, other forms of understanding do not impose such a requirement. Thus, in predicting what legal officials will do, we do not always expect that their actions will comport with our own judgments about the most coherent or the most just continuation of the law. We may think that a certain line of cases should be continued in a particular way, but we may doubt that authoritative decisionmakers will agree. On the contrary, we may believe that they will introduce an undesirable incoherence into the law. When we attempt to persuade judges or other legal decisionmakers to interpret law in our favor, the most persuasive account of law for that audience may leave the law far less coherent than we would like, but our goal is to appeal to the decisionmaker's view of coherence, not our own. ${ }^{38}$

When our goal is to persuade others to change the law, our account of law may be specifically designed to show it as partly incoherent, because one of the ways we may seek to convince others to change existing doctrine is to demonstrate its incoherence or the superior coherence of our proposed solution. Here we employ the tools of rational deconstruction. Similarly, when we criticize the decisions of legal authorities, we do not always endeavor to portray the law in its most coherent light. Rather, our goal is to point out its inadequacies.

Finally, if our concern is the practical effects of legal norms, questions of coherence or incoherence may be wholly irrelevant. Because one cannot know the practical effects or practices of application of a legal doctrine in advance, there is no guarantee that the result will be normatively coherent. Moreover, one purpose of studying the effects of legal norms in practice may be to offer critiques based on the arbitrary results we discover.

38. See Sanford Levinson, What Do Lawyers Know (And What Do They Do With Their Knowledge)?: Comments on Schauer and Moore, 58 S. CAL. L. REv. 441, 455-56 (1985). 
To be sure, each of the above varieties of legal understanding may intersect with and make use of rational reconstruction. Our predictions about the behavior of legal decisionmakers and our attempts to persuade them may require us to imagine how they would rationally reconstruct the law; if their beliefs are similar to our own, then our own rational reconstruction of legal norms will be helpful in this task. Conversely, if our goal is to persuade others to change the law, we may appeal to an alternative that is rationally reconstructible, at least in the eyes of our audience..$^{39}$ Finally, we may find rational reconstruction useful even in our study of the practical effects of doctrines in action. One way to understand the law's effects is to look at the content of authoritative legal norms. Rational reconstruction may be helpful in this enterprise, although a prediction of how others will rationally reconstruct the law may be even more helpful.

Nevertheless, these forms of legal understanding are distinct from rational reconstruction. In predicting what legal decisionmakers will do or in attempting to persuade them to decide in our favor, we must bow to the values and predilections of the legal decisionmakers we attend to. Implicit in our attempts to critique the law and persuade others to change it is a claim that the law is not as coherent as it could be. Our search for the effects of law necessarily contemplates the possibility, which the realists made famous, of a divergence between "law on the books" and law in action. We may not be able to deduce the effects of the legal system from the content of the legal norms that form the subject of rational reconstruction. Even our ability to predict what a particular legal decisionmaker will do (i.e., that Justice $S$ will vote to strike down a particular affirmative action program) does not necessarily result in knowledge of the effects of the decisionmaker's act (i.e., the social consequences of holding such affirmative action programs unconstitutional). What people do is not the same as the effects of what they do. One can know the first without knowing the second.

Although we can see connections between the activity and attitude of rational reconstruction and other purposes in legal understanding, we should not assume that rational reconstruction is the master form of legal understanding to which all other forms are subsidiary. One could also see rational reconstruction depending in part on other forms of legal understanding. I have already noted rational reconstruction's debt to the tools of rational deconstruction. Similarly, in order to decide whether legal norms are rationally reconstructible, we may need to understand how they would be applied by others, and we must gauge their practical effects in the real world.

Instead of viewing rational reconstruction as the central case of legal understanding, accompanied by a set of auxiliary or special forms of legal

39. Often we will claim that the rest of the law is rationally reconstructible, and this counsels in favor of changing the part we do not like in order to achieve normative consistency. 
understanding parasitic on it, I propose a different picture: a set of differentiated yet mutually dependent forms of legal understanding that we employ as the need arises to make sense of the world around us. We must not forget that our understanding of law is always in the larger service of making the social world coherent to ourselves. From this perspective, it makes sense to think of legal understanding as a set of related hermeneutic instruments or devices. Thus, legal understanding is less a single entity than a set of complementary tools we employ in the larger task of social understanding. ${ }^{40}$ Rational reconstruction then becomes simply one of many devices in our hermeneutical toolbox, a form of understanding that nevertheless may rely upon and interact with others even as they rely upon and interact with it. Legal understanding, then, is a complicated encounter with the social world in which we employ whatever tools of understanding seem appropriate to the task at hand.

The plurality of forms of legal understanding may explain the persistence of the predictive theory of law-that law is what the courts will do-despite the repeated criticisms that have been levelled at it. ${ }^{41}$ Jurisprudence professors wrongly seek to judge the predictive theory as a unitary jurisprudential theory. But the predictive "theory" of law is not a jurisprudential theory at all; prediction is simply one purposive activity among many others that individuals use to understand law. One might think that this approach to law articulated a theory of "what law is" only if one forgot the purposive and situated component of all legal understanding; that is to say, only if one forgot the subject's essential contributions to the cultural object it perceives. Of course, this is precisely the occupational hazard of traditional jurisprudence. In this way the person who understands law for the purpose of rational reconstruction and the person who understands law for the purpose of prediction might each believe that they are engaged in the same enterprise-describing law's nature-and that the other party is mistaken in her assertions. In fact, each is merely projecting her situated, purpose-driven subjectivity onto the object of their study and giving it the name of "the theory of law."

40. See COTTERRELl, supra note 37 , at 229.

41. See HART, THE CONCEPT OF LAW, supra note 13 , at $40-41$.

42. The most famous statement of the predictive theory is Oliver W. Holmes, The Path of the Law, 10 HARV. L. REV. 457 (1897). I tend to agree with William Twining's view that both Holmes' admirers and his detractors have unfairly read Holmes' remarks on prediction as offering a generalizable "theory of law"; compare RICHARD A. POSNER, THE PROBLEMS OF JURISPRUDENCE 221-28 (1990) with HART, THE CONCEPT OF LAW, supra note 13, at 40-41. See WILliaM TWINING, KARL LLEWELLYN AND THE REALIST MOVEMENT 18 (1985 ed.). As Twining argues, in The Path of the Law Holmes viewed law in terms of practical activity. Id. Lawyers, Holmes says, are in a business: the business of offering predictions about what courts and other legal officials will do. Twining has rightly complained that Holmes has too often been misread by forcing his words into the mold of jurisprudential theory, rather than recognizing him as offering a description of a practice of understanding by legal professionals. Id.; see also Sanford Levinson, Frivolous Cases: Do Lawyers Really Know Anything at All?, 24 OsGOODE HALL L.J. 353, 363 (1986); William Twining, The Bad Man Revisited, 58 CORNELl L. REV. 275, 292 (1973). 
explaining law wholly in terms of rational reconstruction offers no more of a unitary theory of law than the predictive theory; rational reconstruction is merely one among many purposes in understanding law and can claim neither primacy nor the title of "the internal perspective."

This analysis might also explain why the debate between positivism and some forms of natural law theory also seems never-ending. I am not concerned here with natural law theories that claim that law is simply that which is just, but rather those theories that claim that moral reasoning is inextricably linked to law and legal understanding. ${ }^{43}$ These theories are projections of the experience of rational reconstruction, in which we must view the law as the embodiment of substantive reason. The law appears to have a moral component because the very form of understanding through which we apprehend law in order to apply it to concrete cases requires us to imbue law with substantive rationality. Yet once again, this experience of a moral component does not reveal the nature of law so much as the nature of the projection of our subjectivity onto the legal object of our understanding. Other purposes in understanding law need not imbue law with substantive rationality and therefore need not produce the same hermeneutic effect. The natural law advocate is correct that law is inescapably linked to morality only to the extent that a certain activity of legal understanding requires us to see it in that light, but the advocate is incorrect in deeming that form of understanding central or exclusively revelatory of the nature of law.

We must resist the dual temptation of believing in a single internal perspective that reveals the nature of law and then identifying that perspective with rational reconstruction. The temptation arises because rational reconstruction seems to match the type of legal understanding judges employ when they apply the law. The judge's purpose in understanding law is to make sense of a jumbled mass of precedents, statutes, and administrative regulations and to infer from these a coherent scheme of legal regulation that she can apply to the case before her. However, because there are many different purposes in understanding law, and many different social roles in which legal understanding occurs, we cannot pick out one form of understanding practiced by particular legal elites and bestow upon it the title of "the internal perspective"-the perspective that, as Raz contends, ${ }^{44}$ reveals the nature of law and determines its coherence or incoherence. ${ }^{45}$

I believe that the misreading of Holmes is due in part to jurisprudence's demand for a unitary theory of law which abstracts away from the practical (and hence purposive and situated) nature of legal understanding; the ink spilled over the merits of the predictive theory tells us more, in my view, about the ideological filters of traditional jurisprudential thought than it does about either Holmes or the nature of law.

43. An example would be LON L. FULLER, THE MORALITY OF LAW (1964).

44. Raz, The Relevance of Coherence, supra note 13, at 293.

45. For a similar argument, see COTTERRELL, supra note 37, at 228-31. In Raz's defense, I should note that he has also been critical of the lawyer's perspective in other contexts. See, e.g., Joseph Raz, The 
Belief in a single internal perspective and its identification with rational reconstruction has several unfortunate ideological effects. ${ }^{46}$ First, it makes the other purposes of legal understanding and the other social roles in which understanding occurs irrelevant, conflates them with rational reconstruction, or else relegates them to a peripheral and dependent status. To the extent that alternative forms of legal understanding are recognized, they are depicted as deviations from or modifications of legal understanding that must be understood in terms of their variance from the norm and that may not contradict its conclusions.

Second, this identification makes invisible the subject's contribution to the particular form of legal understanding dubbed "the internal perspective." It divorces this form of understanding from both the purpose giving rise to it and the social group employing that purpose. It presents rational reconstruction employed by judges and other legal elites as legal understanding simpliciter, unconnected to a particular purpose or position. It portrays rational reconstruction as an understanding that does not impose "special" purposes like prediction, political activism, or social scientific study on the legal object, but simply observes the legal object as it is. The social role and purpose of the judge engaged in rational reconstruction become the hidden norm of legal understanding against which all other forms of legal understanding are seen as special pleading, deviant, irrelevant, or mistaken. Simultaneously, the contributions of the judge's social role and purpose are projected onto the law and given the name "the nature of law."

Ronald Dworkin's theory of law as integrity exemplifies these confusions. Dworkin identifies legal understanding with judicial methods of rational reconstruction; indeed, his goal is to explain the internal experience of judging and to reveal the ideals that lie behind judicial practice. ${ }^{47}$ There is nothing wrong with offering a normative or descriptive theory of judicial understanding if it is understood and labeled as such. The problem is that Dworkin believes that explicating this form of legal understanding also explicates the nature of law, or, in Dworkin's language, when "propositions of law are true."48

To speak in this way makes the subject, her purposes, and her preconceptions disappear from view. Interpretation has become purposeless and subjectless. For all of his concern with the interpretive character of law, Dworkin's theory depends on making the contributions of subjectivity invisible

Problem About the Nature of Law, 21 U. W. ONT. L. REV. 203 (1983).

46. COTTERRELL, supra note 37 , at 229 (noting that traditional jurisprudence becomes "mystificatory" and a "professional ideology" when it assumes that what is being discussed is the nature of law rather than a particular mode of thought that lawyers engage in).

47. See, e.g., DWORKIN, supra note 8, at 94 (arguing that theory of law as integrity is "the best interpretation of what lawyers, law teachers, and judges actually do and much of what they say").

48. Id. at 225 ("According to law as integrity, propositions of law are true if they figure in or follow from the principles of justice, faimess, and procedural due process that provide the best constructive interpretation of the community's legal practice."). 
to the discourse of jurisprudence. The fact that judges are socially situated individuals who interpret the law for a particular purpose and bring a particular set of sociological and ideological predispositions to their acts of understanding becomes irrelevant to Dworkin's discussion of legal understanding. By assigning the contributions of subjectivity to the nature of law, Dworkin makes these contributions invisible and all-powerful. Hence, Dworkin is able to exclude all sociological or ideological analysis-the very analysis of what the subject does bring to the object of understanding - as "external critiques" that can tell us nothing about the nature of law. So hermetically (and hermeneutically) sealed is Dworkin's universe that it becomes impossible to object that the concerns of judges occupy only one rather limited position in the constellation of legal reality and the forms of legal understanding.

This error is compounded by Dworkin's general approach to interpreting social practices, of which legal understanding is only a special case. According to Dworkin, interpretation of social practices is always "constructive interpretation"-an attempt to identify the point of a social practice and to see it in its best light. ${ }^{49}$ In this way Dworkin obscures not only the many different forms of legal understanding, but also the many different forms of nonlegal understanding. After all, not all forms of social understanding portray the object of interpretation in its best light. When we describe the injustices of our society in order to convince others of the need for change, we do not attempt to view the object of interpretation in the best possible light; similarly, when we criticize a work of art as badly conceived and executed, we do not describe it in its best light. In both cases, we seek to expose its flaws, blindnesses, and incoherences. This is not rational reconstruction but rational deconstruction. Dworkin's constructive interpretation is not the only form of cultural understanding. It is cultural understanding for a particular purpose; it is one of the many different activities that are collectively called understanding.

In fact, the plurality of forms of cultural understanding is revealed by Dworkin's own practices of argument in Law's Empire; his theory of interpretation is undermined by attending to what he actually does, rather than what he says he is doing. Although Dworkin insists upon the primacy of constructive interpretation, he does not practice what he preaches, nor could he, given the multiple purposes of understanding. When he describes and criticizes the work of the Critical Legal Studies movement, for example, constructive interpretation and interpretive charity are thrown out the window. ${ }^{50}$ Rather, his quite understandable purpose is to point out the

49. Id. at 52 .

50. Dworkin's interpretations of Critical Legal Studies do not evidence any serious attempt to offer the strongest, most coherent, or best possible interpretation of Critical Legal Studies arguments. Rather, Dworkin dismisses this entire body of scholarship in five pages and two lengthy footnotes. See id. at 27175. His depiction of CLS "acolytes" as people who "assemble in conferences" to "decid[e] what the 
inaccuracies and flaws in theories whose conclusions cast doubt on his own. Dworkin may justly be criticized for failing to offer the strongest account of CLS positions before attacking them, which is merely to say that he employs the principles of constructive interpretation and charity inconsistently and opportunistically. ${ }^{51}$ But there is a more important objection: he has failed to acknowledge that having offered the strongest account of a position, an important and distinct purpose in understanding is to recognize the flaws and mistakes in the object of interpretation. In legal understanding, this is the moment of rational deconstruction.

That jurisprudential scholarship might identify the nature of law with elite legal understandings of rational reconstruction makes perfect sense from a critical perspective. It is yet another example of the legal subject projecting the contributions of her subjectivity-her social situation and purposes for understanding-onto the object she seeks to understand. Rational reconstruction is how students of law are taught to understand law, how litigators are taught to argue law, and how judges are expected to write law. Rational reconstruction is the most conspicuous form of legal understanding employed by professional elites, and, more particularly, by the most powerful and central of professional elites, the judiciary. It therefore becomes what legal understanding is. ${ }^{52}$

movement is," id. at 271 , does not seem promising, at least if his goal really is interpretive charity.

According to Dworkin's own theory of constructive interpretation, he should have spent considerable time carefully going over CLS scholarship, trying to make sense of its conflicting assertions, and developing a coherent set of arguments to support its positions. If, as Dworkin argues, "the literature of critical legal studies announces rather than defends [its] claims" about the coherence of the legal system, id. at 272-73, the constructive interpreter should, like the interpreter of legal doctrine, try to fill in the theoretical underpinnings for herself, so as to make the theory the best it can be. Finally, the constructive interpreter, rather than imposing her own purposes on the enterprise, must attempt to understand what the purposes of the enterprise are to the persons who participate in it, and decide what the best explanation and continuation of those purposes are. She must not assume, as Dworkin appears to, that the theoretical importance of Critical Legal Studies rests solely on whether "its aims are those of law as integrity," id. at 275; that is to say, whether it can be usefully employed to further the development and acceptance of Dworkin's theories about law. This is an exclusively instrumental stance which does not seek true understanding because it does not open itself up to the possible truth of what it seeks to understand. See HANS-GEORG GADAMER, TRUTH AND METHOD 270 (Garrett Barden \& John Cumming trans., 1975) (criticizing such instrumental interpretations as attempts to preserve one's own beliefs from question). In short, there is nothing that seems further from the charity-driven account of interpretation offered by Dworkin in chapter two of Law's Empire than Dworkin's own interpretation of Critical Legal Studies in chapter seven of the same book.

51. This tendency is not limited to his accounts of radical scholarship. See, e.g., Charles Silver, Elmer's Case, A Legal Positivist Replies to Dworkin, 6 LAW \& PHIL. 381, 381-82 (1987) (noting that "Dworkin rarely asks whether an argument he calls positivistic is the best argument a Legal Positivist could make.").

52. Note in particular that viewing legal coherence in terms of rational reconstructibility of the content of legal rules projects away considerations of legal application and enforcement by judges, juries, administrative agencies, police officers, social welfare caseworkers, and the like. It focuses our attention on that aspect of law that can be understood through a comparison of the content of legal norms described on paper. Hence we do not focus on exercises of power and injustice that work beneath the economy of rules, the performative aspect of legal doctrine and legal writing, and the irrelevance of much normative legal scholarship to law as it is practiced. See Schlag, Normativity and the Politics of Form, supra note 2, at 852-70 (offering an account of "L.A Law's Empire"). Schlag's analysis, in turn, recalls Jerome Frank's 
Although there is nothing wrong with elites employing distinctive forms of understanding, a difficulty arises when these elites assume that a particular form of legal understanding discloses the real nature of the legal system. By forgetting the different purposes of understanding and the socially situated nature of understanding, they may elevate a particular form of understanding, useful as it may be in a particular context and for a particular purpose, to a universal status. ${ }^{53}$ When jurisprudential discussions assume that the activity of rational reconstruction discloses the true properties of the legal system, they engage in this error. That is why attention to the subject of legal understanding is helpful: it asks us to think about who is understanding the law and for what purposes. It reminds us that there is no understanding of the social world without a subject who understands and a purpose for understanding, and hence no understanding of the social world without the contributions of subjectivity.

\section{The Production of Rational Reconstruction}

Our argument so far has considered the question of legal coherence sociologically as well as philosophically. Judgments of legal coherence arise from a specific form of understanding-rational reconstruction-that is employed predominantly although not exclusively by legal professionals. We have also noted the ideological tendency to privilege this form of understanding in jurisprudential discussions. This section discusses how judgments of rational reconstruction are produced; it considers how these judgments are affected by the experiences and beliefs of the legal professionals who make them. ${ }^{54} \mathrm{I}$ discuss three features of subjectivity that shape our ${ }^{55}$ judgments of rational reconstruction. The first is the state of our moral and political beliefs, the second is the state of our knowledge about the legal system, and the third is the state of our efforts at rational reconstruction through considering possible conflicts of value between legal doctrines. Finally, I argue that the contributions of subjectivity do not merely lead to disagreements among and mistakes by legal professionals. They also facilitate, regulate, and limit professional judgments of rational reconstruction. They are the source of both disagreement and agreement, of both mistakes and correct judgments as viewed from the perspective of dominant conventions of understanding.

realist critique. JEROME FRANK, COURTS ON TRIAL: MYTH AND REALITY IN AMERICAN JUSTICE (1949); JEROME FRANK, LAW AND THE MODERN MIND (1930).

53. See COTTERRELL, supra note 37, at 229; Schlag, Normativity and the Politics of Form, supra note 2 , at 843-852.

54. Part V, infra, discusses the converse problem: how the practice of rational reconstruction affects the beliefs and attitudes of legal professionals.

55. I use the terms "our" and "we" in these passages for two reasons. First, I assume that my audience is fellow legal professionals, and more particularly, fellow legal academics. Second, everything that I say about professional judgments of rational reconstruction applies. to my own judgments as well. 


\section{The Effects of Moral and Political Beliefs on Rational Reconstruction}

The dialectic of hypothetical and actual justification presupposes that our judgments of legal coherence are shaped by our judgments of political morality. Judgments of coherence and incoherence cannot be fully separated from political and moral beliefs because these beliefs help us construct our judgments. Individuals with different political and moral beliefs will tend to define the boundaries of bona fide principles and policies differently; they will also tend to differ on whether balances among them have been struck in a principled and consistent manner. Hence they may reach different conclusions about the rational reconstructibility of a particular area of law.

The contributions of political and moral belief to our judgments of coherence and incoherence are most obvious when they produce disagreement. Yet our political and moral beliefs help construct our judgments of legal coherence even when there is considerable consensus. The social construction of subjectivity produces consensus by creating individuals who think, act, and believe in roughly similar ways. Our judgments of political morality are part of the hermeneutical baggage we bring with us in our attempt to understand the legal system; we should not confuse the fact that each of us brings similar baggage with the claim that we bring no baggage at all.

In like fashion, we must resist the temptation to see political ideology as merely an obstacle or hindrance to our understanding of law. Our political and moral beliefs are necessary tools of legal understanding - they make judgments of normative coherence and incoherence possible. Hence, political ideology does not simply distort or detract from legal understanding; it actively assists in the construction of the legal object of interpretation, both in the case in which we disagree with others and the case in which we agree, both in the case in which the coherence of legal doctrines is disputable and the case in which their coherence seems so obvious that it goes without saying.

\section{The Effects of Legal Knowledge on Rational Reconstruction}

Discussions of legal coherence that treat coherence as a property of a legal object normally bracket away questions about the state of our knowledge of the legal system. In the alternative, they assume a subject with complete knowledge of the legal system, one who sees the law as it really is. ${ }^{56}$ The assumption of complete knowledge makes the legal subject irrelevant to questions of coherence; she becomes a mere vessel into which the real content of a law existing independent of understanding is poured. Nevertheless, our actual judgments about the coherence and incoherence of the law must depend

56. For example, in Ronald Dworkin's theory, the law is coherent to the extent that it is coherent to an ideal judge with perfect knowledge of the legal system. See DwORKIN, supra note 8, at 265. 
heavily on our knowledge of the content of existing legal norms and their effects in application. Our knowledge of "what the law is"-in the sense of what the actual decisions of courts and promulgations of legislatures and administrative agencies are-is remarkably limited, even for individuals who regularly practice law. There is simply a huge amount of law that even socalled experts are not aware of, and their knowledge of the practical effects of existing legal norms may be even sketchier. ${ }^{57}$

If we are not aware of the content of legal norms in many different parts of the law, they cannot figure into our awareness of possible sources of moral conflict and normative incoherence. Moreover, if our knowledge is focused in a few areas of law, our opinions about the coherence of other parts of the law and of the legal system as a whole are likely to be informed by our opinions and our experience of the limited areas we do know. ${ }^{58}$ Our judgments about the coherence of the legal system therefore must derive largely from our image of the legal system, an image shaped as much by our ignorance as by our knowledge. We judge based on what we know and do not know, and, equally importantly, on what we do not know we do not know.

Our judgments of legal coherence and incoherence are affected not only by our knowledge of legal doctrines, but also by the amount of cognitive effort we have put into considering the normative consistency among the doctrines we do know. After all, justifications that make sense to us at first glance often become problematic on further reflection, and vice versa. ${ }^{59}$ However, most people (law professors included) have not thought very hard about the various justifications for the content of most legal doctrines; indeed, they may have neither the time nor the ability to consider all of the possible justifications or conflicts among justifications that might be offered within the many areas of legal doctrine. ${ }^{60}$

57. I should note that this is particularly true of legal theorists who write about topics like legal objectivity, legal coherence, and legal justification. I teach torts and federal constitutional law, and therefore can have some claim to expertise in these areas. However, I am only dimly aware of the vast number of decisions reached in these areas by courts, to say nothing of relevant legislative and administrative regulations. Furthermore, there are large parts of legal doctrine where my knowledge is incredibly skimpy, and others where I am not even aware of the existence of legal regulations, much less their content or their effects. Hence, a great deal of the legal system that I talk about, think about, and write about is the product of my imaginative extrapolation. I do not believe that my situation is in any way atypical, especially of professors of jurisprudence.

58. For example, people who teach common law subjects or constitutional law (as I do) may tend to overlook what occurs in areas of law governed largely by statute and administrative regulation. Law professors may tend to emphasize the content of legal norms rather than their practical effects because they teach the former and not the latter.

59. See Duncan Kennedy, Freedom and Constraint in Adjudication: A Critical Phenomenology, 36 J. LEGAL EDUC. 518, 531-33 (1986) (discussing changing appearances of "field" of judicial precedents as we work to understand and employ them).

60. Moreover, they may have little knowledge of how legal doctrines in these diverse areas are applied in practice and what effects they have on individuals; as argued above, these practical effects are relevant to the coherence of doctrines. In this respect, the professor of jurisprudence is hardly better equipped than the ordinary person on the street. 
The problem is magnified when we move from considerations of coherence in a specific area of law to questions of coherence across doctrinal areas or the legal system as a whole. Few people have considered all the possible conflicts among rules across different areas of law. Compartmentalization of law into different subject areas probably exacerbates this phenomenon; we simply do not think to ask whether the way we argue in tort law is consistent with the principles we use in the law of trusts and estates, the law of mineral rights, or the law of mass communication. In any case, it may well be impossible for any one person or group of persons to develop a global justification and reconciliation of legal materials or a comprehensive understanding of the law's effects. Because we cannot conceive of the legal system as a totality, and because we cannot hope to subject all of the different aspects of the legal system to the most searching analysis, we must fall back on assumptions about the coherence of the legal system based on our limited experiences and our existing ideological commitments. Hence, our judgments about the coherence of the legal system or parts thereof may be as much matters of faith and ideological presupposition as the consequence of reasoned analysis. We construct an imagined legal system from equal parts of ignorance and experience, and it is against this image that we test our visions of justice. Our judgments of coherence are not simply judgments about properties of the legal system, but rather judgments of imaginative reconstructions of the legal system as it is believed to exist. The constructed object of interpretation is also the constructed object of our imagination.

\section{Rational Reconstruction's Debt to Subjectivity}

My focus on our lack of knowledge and circumspection in our judgments of coherence may seem both obvious and irrelevant. Of course people make mistakes in judgment, one might object, but what has that to do with the question of legal coherence? Legal coherence is a question of what the law really is, not a question of what people mistakenly assume it to be. Yet this objection exemplifies the basic difficulty in accounts of legal understanding that dismiss the contributions of subjectivity. It considers legal coherence purely from the standpoint of an object that is constituted independent of human consciousness. This misunderstands the nature of legal understanding. Legal coherence is a hermeneutic feature of law. It is the result of an interaction between a legal subject and a legal object already constructed by the legal subject. One might wish to abstract away the question of legal coherence from the vagaries and insufficiencies of legal subjects. But this is a fool's errand. There is no judgment of legal coherence that is not made by a legal subject. The experience of legal coherence is always by somebody or someone. There is no one else to do the job. 
This conclusion may seem unsatisfying because we naturally assume that there is a fact of the matter about the coherence of the law quite apart from the intrusions of subjectivity. But subjectivity is not an intrusion into law-it is a constitution of law. Thus, there is a fact of the matter about legal coherence, but it is of a quite different sort. The fact of the matter is that legal coherence is the product of a hermeneutic interaction. It is the result rather than the object of a process of understanding.

The inseparability of legal coherence from subjectivity has two important consequences. First, our experience of legal coherence is necessarily grounded in our social situation and in the manner in which we encounter the law. We occupy different positions in society and experience the legal system in different ways. Understandings of the legal system differ for a trial judge in a court of general jurisdiction, a practicing tax attorney, a recidivist criminal, a twenty-three-year-old secretary who has never received any more serious legal sanction than a parking ticket, a businessperson in the midst of a child custody battle, a social scientist, a first-year law student, and a professor of jurisprudence. Merely to list these different social situations is to note the many possible forms of legal understanding and the many different sorts of experiences that individuals can have. Rather than viewing this plurality of experiences as distractions from legal understanding, we should recognize that this is what legal understanding consists in. There are no subjectless encounters with the law.

Second, our experience of legal coherence or incoherence is dynamic. Our experience of the content of the legal system changes over time as we have new experiences, engage in deeper analyses of possible conflicts of value between doctrines, and become aware of the effects of doctrines in action. Our judgments about and understandings of the legal system are always in a process of change. Our continuing experience as individuals in a legal system changes our understandings as to what is in the system, whether particular distinctions and similarities are tenable or untenable, and so on. Legal understanding, and hence legal judgment, is always in a process of flux..$^{61}$ It is dynamic, not static, because our knowledge and experience of the object of understanding is dynamic.

One might hope to avoid these conclusions by employing an "ideal observer" theory of legal coherence. Under this theory, we would say that the law is coherent if it would appear coherent to an ideal observer. ${ }^{62}$ Thus,

61. See Kennedy, supra note 59.

62. Cf. Roderick Firth, Ethical Absolutism and the Ideal Observer, 12 PHIL. \& PHENOMENOLOGICAL REs. 317 (1952) (proposing naturalistic theory of ethics that defines "good" as that which an ideal observer would approve). Ronald Dworkin's Hercules plays a role similar to an ideal observer of law. See DwORKIN, supra note 8, at 265 ("Hercules is useful to us just because he is more reflective and self-conscious than any real judge need be or, given the press of work, could be. ... He does what [judges] would do if they had a career to devote to a single decision ...."). 
although some individuals might incorrectly perceive certain elements of the law as coherent or incoherent, they are mistaken to the extent that their conclusions diverge from those of an ideal observer of law. An ideal observer theory would preserve the subject's centrality to legal understanding while simultaneously offering a standard of objectivity that abstracts away from subjectivity.

The ideal observer view is attractive because it points, however obliquely, to a number of sound intuitions about our experience of the law. First, our views of the law are revisable. Upon further reflection, and given further information, we may sometimes change our minds as to whether a distinction is tenable or untenable, whether a doctrine is just or unjust, and so on. ${ }^{63}$ Second, we know that some judgments about the law are better than others, although it does not necessarily follow that all judgments for all purposes in understanding law can be ranked in order from best to worst. ${ }^{64}$ Third, we generally believe that legal judgments are better when the individual who makes them has access to more information, and has thought a lot about the issues involved. ${ }^{65}$

The postulation of an ideal observer is an extrapolation from these three eminently sensible views about legal judgment. The extrapolation itself, however, is misguided. Just because our views about law are revisable does not mean that there is a final unrevisable view. Just because some legal judgments are better than others does not mean that there must always be a single judgment that is better than all others. Finally, just because more thought and more information generally lead to better judgments does not mean that taking infinite time and possessing all information leads to a univocal, correct judgment.

More importantly, the ideal observer theory fails to grasp the nature of legal knowledge. Knowledge of a cultural artifact like law must always result from our situatedness in a particular social and historical tradition. ${ }^{66}$ This situatedness is not a hindrance to cultural understanding but rather the ground of its possibility ${ }^{67}$ The problem of legal understanding is a special case of the problem of human understanding of culture generally. Cultural traditions

63. Of course, this is not always the case; sometimes our initial judgments remain unchanged even after considerable deliberation.

64. For example, it may be difficult to tell whether A's judgment about the law made for the purposes of prediction is better than B's judgment made for the purposes of rational reconstruction. Such comparisons are possible only if we insist on a single standard of commensurability for all legal judgments, regardless of purpose. If we do this, we may not be satisfied with the results because the single criterion for judgment may be orthogonal to our purpose for understanding the law in a given case.

65. Here, too, there are exceptions; too much information, like too much puzzling over making cases coherent, can sometimes befuddle us.

66. See JOHN B. THOMPSON, IDEOLOGY AND MODERN CULTURE 276-77 (1990). This idea is central to Hans Georg Gadamer's ontological hermeneutics. See the discussion of Gadamer's views, infra Part V.A.

67. See Jerome BRUNer, ACTS OF MEANING 11-15, 20-21 (1990); ClifFord GeERTZ, THE INTERPRETATTON OF CULTURES 50-51, 82-83 (1973). 
constitute us as human and make possible our understanding of culture. Hence human beings are always part of culture and not merely disinterested spectators. Even when we attempt to understand a culture that is not our own, we bring our own "cultural software" as necessary tools of understanding. We always understand from a historical and cultural position, just as we always measure velocity or acceleration from a particular point in space. Without a place to start from, we cannot understand anything at all.

It follows that if the understanding of the ideal observer is truly a human understanding, she too must be the product of a particular history and a particular cultural situation. However, this is precisely what an ideal observer theory resists, because it assumes that historical and cultural situatedness is a bias that must be neutralized or abstracted away. The ideal observer approach views as an obstacle to understanding what is in fact a condition of understanding.

If the ideal observer's understanding is truly a human one, we must ask several questions about this observer: Of what culture is she a part? What is her history? What are the wellsprings of her understanding? Merely attempting to answer these questions with respect to an ideal observer shows the limitations of the theory. Shall we say that the ideal observer lives in no culture at all? Then how is she able to understand any culture? Shall we say that the ideal observer comes from a perfect culture? Which culture is that? Shall we say instead that she comes from our culture? If so, what is it about our culture that makes it ideal? Our culture is not homogenous; from what part of our culture does the ideal observer come? If this part is the ideal, does this mean that the other parts of our culture are less than ideal? Similarly, we might wonder, what experiences has the ideal observer had? Shall we say that the ideal observer has had every experience? If she has, what experience does she currently have, since one cannot have all experiences simultaneously?

We are faced with a dilemma. To imagine an ideal observer is either to imagine a person with no culture, no history, and no experiences, who therefore lacks the conditions of human cultural understanding, or else it is to elevate a particular culture, status, position, and history to the level of an ideal standpoint for observation and thus to forget its partiality.

Ultimately, the turn to an ideal observer is an attempt to avoid thinking about the legal subject and to focus sole attention on the object. It is an attempt to avoid worrying about the legal subject's contribution to understanding by imagining a neutral "plain vanilla" subject who is not doing anything in her encounter with the constructed object of her interpretation. This conception throws the baby out with the bath water. It removes the possibility of understanding along with the biases it seeks to excise. Worse still is the danger that an ideal observer theory may confuse the baby with the bath water: it may unthinkingly equate the ideal observer with the theorist's own cultural and historical situation, and thus may make the theorist's own situatedness 
invisible by defining it as objective. Even plain vanilla is still, after all, a flavor.

Our discussion of the purposive nature of understanding points to a further difficulty. Ideal observers do not have purposes because they are not human beings. They do not have particular desires, motivations, goals, and urges. They just are. Cultural understanding, on the other hand, is grounded in our individual purposes, desires, and aspirations; these in turn are shaped by our social construction. To understand as a human being is to grapple with the world in a particular way because of who we are and what we seek to accomplish. If we wish to apply the concept of an ideal observer to the concept of human understanding we must ask what purposes the ideal observer has in understanding law. Yet to answer this question requires that we place the ideal observer in a particular context-as a human being with limited physical and mental capabilities, with a particular set of goals and aspirations, and with a history that structures and determines them. To capture the human experience of purposive understanding we must also capture the human finitude and situatedness that form the basis for our motivations and purposes in understanding. At the point at which the ideal observer becomes sufficiently particularized so that we can call her understanding a human one, she has largely lost her status as an abstracted, ideal observer.

My point in making these observations is not to deny that in making judgments individuals share a great deal with others. Much of our subjectivity is intersubjective, and this intersubjectivity is a source of objectivity. Yet what we share with others may be cognitive limitations as much as abilities, ignorance as much as information, faith as much as knowledge, and partiality as much as neutrality. The average observer is by no means an "ideal" observer with unlimited time, knowledge, and capabilities. That is what makes her a human, as opposed to an ideal, observer. Ironically, her imperfections and limitations may be what she has most in common with her fellow citizens.

We can preserve the sound intuitions that motivate the ideal observer theory only if we strip the theory of its pretensions to subjectless objectivity. We can employ the notion of an ideal observer as a shorthand when we are speaking about a particular purpose in understanding and a particular cultural standpoint. There is nothing wrong with saying that for a particular purpose (for example, rational reconstruction), or from a particular standpoint (for example, that of a legal professional), one judgment is better than another, because we understand the context in which we are making our judgments. Our goal should not be to deny that we can and do make appropriate judgments about the law and legal coherence. We should merely recognize the relationship of our subjectivity to the standard of appropriateness. ${ }^{68}$

68. Thus, it should not be surprising that legal professionals generally make better judgments about the law than laypeople according to the criteria that professionals set for themselves and that distinguish 


\section{Legal Coherence as Reduction of Cognitive Dissonance}

In our earlier discussion of the different varieties of coherence, I noted the special nature of the coherence of the world. The coherence of the world derives from the self's need to believe in its own coherence. The world must make sense to us because we must make sense to ourselves. Accounts of coherence in the social world are driven by our need to believe that our own beliefs are ordered, coherent, and rational, and that we are rational, morally sensitive individuals. To do this, we may need to conclude that certain parts of the social world are lacking in logical, normative, or narrative coherence-that a certain person is behaving unreasonably, that a certain argument makes no sense, that a certain legal doctrine makes arbitrary distinctions, and so on. We can make the world coherent by assuming the coherence or the incoherence of specific and limited parts of it, including those parts of the social world we call law. That is because the need to preserve beliefs about the self is prior to judgments about the coherence of any part of the social world, including the legal system. If we hope to understand the subject's contribution to the nature of the law she observes, we must consider how the preservation of the self's beliefs about itself shapes and motivates its judgments of legal coherence.

We can explore the relation between our beliefs about ourselves and our beliefs about law through the psychological theory of cognitive dissonance. When faced with inconsistent beliefs and attitudes, we engage in cognitive work to reduce the resulting dissonance. ${ }^{69}$ Thus, we might believe what we do about the coherence or the incoherence of the law because it reduces cognitive dissonance. This possibility places debates about legal coherence in a very different light. Legal coherence becomes not a desideratum for law but a strategy of self-affirmation; legal incoherence becomes not a focus for political critique but a method for externalizing internal conflict. The question becomes not whether the law is coherent or incoherent but why it is important that the law appear coherent or incoherent and what steps legal subjects will take to ensure that it appears that way.

People reduce cognitive dissonance in many ways. They selectively recall events, reinterpret them, or reduce the importance of different elements in what they recall. ${ }^{70}$ They compartmentalize situations to avoid considering them

them from laypeople generally. If they did not make better judgments under these criteria, they would probably not be very good professionals because they would have failed to distinguish themselves successfully from nonprofessionals.

69. See J. RICHARD EISER, SOCIAL PSYCHOLOGY: ATTITUDES, COGNITION AND SOCIAL BEHAVIOUR 90 (1986); SuSAN T. FiSke \& SHELlEy E. TAYLOR, SOCIAL Cognition 467-68 (1991).

70. EISER, supra note 69 , at $90-92$ (1986). For example, we can rationalize our continued smoking in the face of evidence that smoking is dangerous by emphasizing its benefits (it keeps our weight down), deemphasizing its disadvantages (telling ourselves that we will all die eventually anyway), or introducing other beliefs that preserve our self-image of rationality (I know that it's bad for me, but it's not my fault 
together. People sometimes reject or de-emphasize information or interpretations inconsistent with attitudes they hold and previous actions they have taken while favoring consistent information or interpretations. They do this by selectively focusing on past experiences that support their beliefs and behaviors while downplaying or forgetting experiences that do not support them, by selectively focusing their attention on parts of current experience that support their beliefs and actions, or by selectively interpreting events to resolve ambiguities in favor of consistency. ${ }^{71}$

Dissonance theory does not require that individuals adopt any particular mode of dissonance reduction. ${ }^{72}$ It merely predicts that when dissonance occurs, it will lead to a change in behavior, beliefs, or attitudes. Some beliefs are more important to people than others. These beliefs are less likely to be reformed or abandoned. ${ }^{73}$ Conversely, people are most likely to modify the dissonant cognitive elements that are the easiest to change or abandon. ${ }^{74}$ Over time, dissonance theorists have recognized that at the heart of dissonance production and resolution is preservation of the concept of self. ${ }^{75}$ Hence, inconsistent cognitions by themselves do not produce dissonance; rather, dissonance arises from cognitions whose inconsistency threatens the self's view of itself. ${ }^{76}$

because I am addicted now and can't stop). See FISKE \& TAYLOR, supra note 69, at 468; see also EISER, supra at 92; Christine McMaster \& Christina Lee, Cognitive Dissonance in Tobacco Smokers, 16 ADDICTIVE BEHAVIORS 349 (1991) (discussing various modes of dissonance reduction).

71. FISKE \& TAYLOR, supra note 69, at 468-69. Sometimes people may even engage in selective exposure to events; that is, they may expose themselves only to information that is consistent with their beliefs and behaviors and avoid situations where they might be confronted by information that would increase cognitive dissonance. Evidence for this method of dissonance reduction is mixed, and some psychologists doubt that people employ it. See ROBERT A. WICKLUND \& JACK W. BREHM, PERSPECTIVES ON COGNITIVE DISSONANCE 189 (1976); Anthony G. Greenwald \& David L. Ronis, Twenty Years of Cognitive Dissonance: Case Study of the Evolution of a Theory, 85 PSYCHOL. REv. 53, 54 (1978). More commonly, people's life experiences reinforce their beliefs de facto because they may already "inhabit an environment that is already biased in favor of positions with which [they] already agree." FISKE \& TAYLOR, supra note 69 , at 469 . Nevertheless, "people tend to pick friends, magazines, and television shows that reinforce their own attitudes, and their attitudes, in turn, are reinforced by those agreeing others." Id.

72. EISER, supra note 69, at 93; Elliot Aronson, The Theory of Cognitive Dissonance: $A$ Current Perspective, 4 ADVANCES EXPERIMENTAL SOC. PSYCHOL. 1, 16-17 (1969).

73. Joel Cooper \& Russell H. Fazio, A New Look at Dissonance Theory, 17 ADVANCES EXPERIMENTAL SOC. PSYCHOL. 229, 258-59 (1984).

74. JACK W. BREHM \& ARTHUR R. COHEN, EXPLORATIONS IN COGNITIVE DisSONANCE 9 (1962).

75. See Aronson, supra note 72; Robert F. Kidd \& Leonard Berkowitz, Effect of Dissonance Arousal on Helpfulness, 33 J. Personality \& Soc. PsyCHol. 613 (1976); Claude M. Steele \& Thomas J. Liu, Dissonance Processes as Self-Affirmation, 45 J. PERSONALITY \& SOC. PSYCHOL. 5 (1983); Ruth Thibodeau \& Elliot Aronson, Taking a Closer Look, Reasserting the Role of the Self-Concept in Dissonance Theory, 18 PERSONALITY \& SOC. PSYCHOL. Bull. 591 (1992). As it developed from Festinger's original conception, cognitive dissonance theory has become "focused on cognitive changes occurring in the service of ego defense, or self-esteem maintenance, rather than in the interest of preserving psychological consistency." Greenwald \& Ronis, supra note 71, at 55.

76. See Aronson, supra note 72, at 27 (" $[\mathrm{A}] \mathrm{t}$ the very heart of dissonance theory, where it makes its clearest and neatest prediction, we are not dealing with any two cognitions; rather, we are usually dealing with the self-concept and cognitions about some behavior. If dissonance exists it is because the individual's behavior is inconsistent with his self-concept."). 
What is the connection between the need to reduce cognitive dissonance and judgments about the coherence of the norms and results produced by the legal system? Conflicts between one's own beliefs and actions are quite different from conflicts between legal norms. People have a stake in the consistency of the former that they may not have in the latter. It is important for people to believe that they are non-hypocritical, consistent, and morally sensitive individuals; it is not always important for them to believe that a set of legal norms is principled, just, or fair. The former beliefs are likely to be central to any individual's self-conception; the latter beliefs may be more easily abandoned, may not be held at all, or may even conflict with other beliefs an individual holds. ${ }^{77}$ People will have a need to alter their beliefs about the legal system or the social world only if their beliefs about the coherence or incoherence of legal norms produce a significant conflict with their other commitments and their sense of self. In such cases, they will employ the various strategies of cognitive dissonance reduction: they will subtly alter their judgments of justice and fairness, selectively redescribe or ignore facts, avoid or deny recalcitrant experiences, and compartmentalize situations in order to reach the conclusion that various legal doctrines are rationally reconstructible or are not amenable to rational reconstruction.

When considering how judgments of legal coherence are affected by the need to reduce cognitive dissonance, we must always trace our inquiry back to the individual's imperative to believe in the coherence of her own moral and political judgments and to believe in herself as a morally sensitive and reasonable individual. The key question is whether an individual has an "ontological stake" in the coherence of the legal system, a particular set of legal doctrines, or a particular political or moral theory she believes is embodied in the law. If she lacks this stake, it may be easier for her to conclude that the legal system (or some part of it) is incoherent than to accept that her own moral and political beliefs might be. Indeed, if an individual has an ontological stake in believing in the fundamental incoherence (or the fundamental injustice) of the legal and political system, she will tend to find unresolved moral conflicts and contradictions in various parts of the law because belief in their coherence might conflict with her precommitments. She may find it helpful to preserve the coherence of her own beliefs by projecting incoherence onto the beliefs of an Other-in this case, the law. ${ }^{78}$

When might individuals have a personal stake in the coherence of the legal system or parts of the legal system? If a person's moral beliefs coincide with a large part of existing law, then an attack on the coherence of legal norms is

77. See id. at 25 (noting that recognition of inconsistent cognitions may not produce dissonance depending on underlying cognition or previous commitments of belief).

78. See Schlag, supra note 3, at 1219 (suggesting that Critical Legal Studies accounts of law may project contradiction onto the legal object, thereby shielding the critic from any possibility that her own thought might be internally conflicted). 
also an attack on her moral judgments. However, most individuals are not aware of the actual content of much of the law and fewer still have considered all of the possible moral conflicts among legal doctrines. Moreover, people often make judgments based on relatively limited factual evidence about the practical effects of legal norms. Despite this, they may still form strong beliefs that various aspects of existing doctrine are normatively coherent even when they have devoted little thought to the possible conflicts between them or are largely ignorant of their content or their practical effects. They will argue fervently for the coherence of existing legal doctrines (as they understand them) when presented with attacks on their coherence. Thus, individuals may have strong commitments to belief in the coherence of the legal system or parts thereof even when they are largely ignorant or mistaken about the content or practical effect of legal doctrines.

What accounts for these features of our moral experience? One explanation is that individuals often engage in simplifying assumptions about the moral consistency and justification of prevailing social norms and arrangements in the society in which they live. For example, they may assume that generally accepted social norms and arrangements make sense and are justified unless there are strong reasons to believe that they are incoherent and arbitrary. Such simplifying assumptions can reduce cognitive work and make understanding the social world easier.

Thus, individuals may have a considerable stake in the belief that prevailing social norms and arrangements are presumptively morally coherent for several reasons. First, to assume otherwise might produce considerable dissonance because a person would be forced to conclude that she lives in a society whose basic norms and arrangements are morally arbitrary or incoherent. People may therefore be strongly committed to believing that they live in a basically just society, and that elements of arbitrariness, unreasonableness, or injustice, are the exception rather than the rule. ${ }^{79}$ Hence they may work on the assumption that legal norms are reasonable and justified both in their content and in their application unless demonstrated otherwise. ${ }^{80}$

79. Such views are consistent with the phenomenon of "belief in a just world." Some social psychologists argue that people have both a tendency and a need to believe that they live in a world that is basically fair and just. People with just world beliefs are more likely to assume that existing social and political institutions are fair and admirable and that disadvantaged people are responsible for their own misfortunes. See EISER, supra note 69, at 264-75; Adrian Furnham \& Edward Procter, Belief in a Just World: Review and Critique of the Individual Difference Literature, 28 BRT. J. SOC. PSYCHOL. 365 (1989). Just world beliefs allow individuals to justify the status quo to themselves even in very unjust societies. See Adrian Furnham, Just World Beliefs in an Unjust Society: A Cross-Cultural Comparison, 15 EUR. J. SOC. PSYCHOL. 363 (1985) (comparing prevalence of just world beliefs in Great Britain and South Africa).

80. Individuals may also have a stake in the coherence of legal norms if the legal system represents authority and they have a strong stake in identifying with authority. Where the legal system becomes identified with general social authority, attacks on the coherence of legal norms may be interpreted as attacks on the society itself. 
Second, the belief that prevailing social norms and arrangements are morally incoherent would require people to engage in considerable cognitive work to arrive at alternative conceptions of the vast number of social arrangements and norms that they unself-consciously understand, apply, and accept. Thus, even people who believe that the society they live in is basically unjust in important respects nevertheless depend heavily on the moral coherence of many concrete social norms and institutions in making their critical moral and social judgments. Indeed, there is an important sense in which almost all dissenting or unorthodox views are parasitic on existing social norms.

Third, people may assume that social and legal norms are the product of considerable thought and effort, or, in the case of social custom, long experience. Hence they may work on the assumption that the legal or social status quo is not only a descriptive but also a prescriptive norm. Existing norms are presumptively coherent and reasonable, whereas deviations from those norms must be justified. In this way people can have a considerable stake in the moral coherence of the status quo (as they imagine it to be) regardless of their knowledge of its content.

Fourth, legal norms may coincide with a person's own norms because the former have helped to constitute the latter. A person's judgments about issues of social regulation may result from her study of the law, particularly if she has not thought much about these issues before she begins her study of the relevant legal doctrines. Thus, although a person's preexisting moral commitments can affect her judgment of the coherence of legal norms, the reverse is also true. A person's experience in working with and understanding legal norms can have the effect of shaping her moral and political commitments and hence her judgments about the legal system. ${ }^{81}$

Fifth, people may have a stake in the coherence of legal norms because they have used them to justify their actions and commitments. Cognitive dissonance is likely to be greatest when people feel personal responsibility for their actions and commitments. ${ }^{82}$ If people justify their previous actions on

81. See the discussion of hermeneutic co-optation infra Part V.B.

82. Roy F. Baumeister \& Dianne M. Tice, Role of Self-Presentation and Choice in Cognitive Dissonance Under Forced Compliance: Necessary or Sufficient Causes?, 46 J. PERSONALITY \& SOC. PSYCHOL. 5, 12 (1984); Greenwald \& Ronis, supra note 71, at 54-55. Thus, the need to reduce dissonance is greatest when a person's commitments will have an adverse impact on herself or innocent parties for which she will be held responsible. LEONARD BERKOWIT, A SURVEY OF SOCIAL PSYCHOLOGY 65 (1986); Cooper \& Fazio, supra note 73. In one experiment, when subjects were asked to make a statement opposed to their beliefs which they knew might mislead and thus harm susceptible children, they were more likely to alter their opinions and adopt the views they had expressed in the statement. Michael F. Hoyt et al., Studies in Forced Compliance: Confluence of Choice and Consequence on Attitude Change, $23 \mathrm{~J}$. PERSONALITY \& SOC. PSYCHOL. 205 (1972). On the other hand, in another experiment, when subjects were told that their statements might lead to harm to an undesirable person, they were less likely to change their attitudes to conform with what they had said. BERKOWITZ, supra, at 65-66; Joel Cooper et al., Mistreatment of an Esteemed Other as a Consequence Affecting Dissonance Reduction, 10 J. EXPERIMENTAL SOC. PSYCHOL. 224 (1974). This suggests that one way to reduce cognitive dissonance might be to change our 
the grounds that their conduct is legal or that the position they have taken is consistent with existing law, then they may have a stake in the coherence of legal norms that justify their behavior. ${ }^{83}$

At first glance, practicing lawyers would seem likely candidates for strategies of dissonance reduction to avoid uncomfortable conclusions about legal coherence and incoherence. Lawyers work with the law every day and are often paid well to argue that various aspects of the law are coherent or lack coherence, often in ways that conflict markedly with their own beliefs. In fact, the situation is more complicated; in some cases, lawyers' financial compensation may actually lessen their urge to reduce cognitive dissonance. Our need to reduce cognitive dissonance arises when we experience a threat to our self-concept or a state of negative arousal. The more negative the experience of dissonance, the greater the urge to reduce it. Conversely, selfaffirming or other positive experiences have the opposite effect; they lessen the urge to reduce dissonance. ${ }^{84}$ As a result, offering people greater incentives to act contrary to their beliefs does not make them more likely to adjust their beliefs to conform with their actions because the incentives act like positive reinforcements. ${ }^{85}$ This relationship explains the results of "forced compliance" experiments that suggest, surprisingly, that individuals who are offered larger sums of money to write essays contrary to their beliefs are less likely to modify their beliefs to conform with their actions than people who are given smaller amounts. A higher payment acts as a greater balm to any negative feelings and hence results in less net dissonance. Conversely, the net negative consequences from behaving contrary to one's attitudes and beliefs are greater when one is offered a smaller payment. ${ }^{86}$

These studies suggest that we should not expect that lawyers will necessarily change their beliefs to conform with those of their clients because they are very well paid to represent those clients. Indeed, the better paid they are, and the more social status they obtain from their lucrative practices, the less net dissonance they will experience, and the less need they will feel to make their beliefs conform with their actions. The less-well-paid lawyer may be more likely to engage in self-justifying adjustment of her beliefs and attitudes. ${ }^{87}$

beliefs about whether persons adversely affected by our actions are really innocent or otherwise deserving.

83. In other words, the belief that one is not the sort of person who takes morally arbitrary actions or has inconsistent beliefs may be bolstered by a belief that one's views or actions accord with settled law and that the law is basically fair and coherent.

84. EISER, supra note 69, at 122; Cooper \& Fazio, supra note 73, at 256.

85. BERKOWITZ, supra note 82, at 216; EISER, supra note 69 , at 94 . In one classic experiment, Yale students were asked to write essays favoring repressive actions by the New Haven Police Department in stopping a student riot. Students who were paid less money came to believe in the truth of what they had written more than students given a greater sum. See BREHM \& COHEN, supra note 74, at 73-78.

86. EISER, supra note 69 , at 94 .

87. Another explanation for these results involves our perceptions of personal responsibility for our actions. Cognitive dissonance is greatest when we feel responsible for what we have done. Acting contrary 
Of course, most accounts of legal coherence and incoherence appearing in law reviews are not written by practicing lawyers or even by judges. They are written by legal academics. Legal academics' social positions give them a somewhat different stake in the order and coherence of legal norms. They defend and critique legal norms and theories about legal norms. Thus we should expect that academics will employ strategies of dissonance reduction when they have a personal stake in perceiving legal norms or theories as coherent or incoherent, and when contrary perceptions would significantly threaten their self-conception. At one level, legal academics have a strong stake in discovering normative incoherence and disorder in the law. Legal academics are expected to say original things about the legal system, and their self-worth is shaped by this imperative. Hence, academics have obvious incentives to find something wrong in existing materials so that they may write articles that demonstrate that there is a better way of reconstructing doctrine. Moreover, although legal academics are usually strongly committed to the coherence of their own theories, they also have incentives to poke holes in the work of previous academics.

Political commitments may also affect academic judgments. Like everyone else, legal academics are more likely to believe that legal norms they agree with are normatively coherent; a contrary conclusion might produce dissonance by casting doubt on the coherence of their own beliefs. Conversely, if they find aspects of the law unjust, they are likely to find them lacking in coherence as well. ${ }^{88}$

Nevertheless, much academic discourse about law depends on the assumption that legal doctrines are generally coherent. Legal academics often use existing doctrines as a background for comparison; they argue that a particular doctrine they are attacking is anomalous because it produces a local failure of coherence. ${ }^{89}$ When an academic proposes a change in or a reinterpretation of law, people implicitly assume that she is claiming that her

to our beliefs for a small amount maximizes our apparent responsibility for the conduct; thus it produces the greatest motivation to alter our beliefs. See Barry R. Schlenker, Translating Actions into Attitudes: An Identity-Analytic Approach to the Explanation of Social Conduct, 15 ADVANCES EXPERIMENTAL SOC. PSYCHOL. 193, 225 (1982).

The classic forced compliance experiments assume that subjects believe that the payments they receive for counterattitudinal behavior are legitimate. On the other hand, if payments are seen as illegitimate, for example, because they are viewed as bribes or as disproportionately large, people may feel an increased responsibility for their actions, which may also lead to a need to alter attitudes to justify their actions to themselves. Id. at 225-27. Hence, there may be a curvilinear relationship between payment size and attitude adjustment; after a certain point, payments seem so disproportionately large that they raise the presumption of illegitimacy and raise anxieties about personal responsibility. Id. This suggests that lawyers who feel they are greatly overcompensated for their work or who believe that the payments being made to them might appear illegitimate are more likely to engage in strategies of dissonance reduction in order to justify their actions to themselves.

88. However, this may pose a less serious threat to self-conception. It is easier to acknowledge that the law does not match one's own beliefs but is still coherent than it is to accept that the law matches one's own beliefs and is incoherent.

89. Lawyers and judges do this as well, of course. 
proposal will make the law more normatively coherent. ${ }^{90}$ If it does not, this will usually be counted as a defect in the proposal. This phenomenon is simply a special case of rational deconstruction's debt to rational reconstruction. If an academic engages in selective rational deconstruction, she must already accept to a large degree the coherence of the system within which she works. Legal academics may simultaneously have a stake in the local incoherence of particular legal norms and the global coherence of a larger set of legal practices they employ as a background test for normative coherence. As before, this stake can produce strategies of dissonance reduction when academics confront perceptions of law that contradict their most deeply held commitments and beliefs.

\section{RATIONAL RECONSTRUCTION'S POWER OVER THE SELF}

\section{A. The Ontological Basis of Rational Reconstruction}

In the discussion of cognitive dissonance I emphasized the importance of our ontological stake in particular beliefs: the connection between our selfimage and a set of beliefs about the social world. This ontological aspect of understanding - that understanding is tied to our selves as selves-can be generalized beyond dissonance theory. In this section, I shall argue that the very process of seeking to understand legal doctrines and applying them to concrete cases-the process of rational reconstruction-engages us and affects our beliefs. Rational reconstruction, in other words, is not merely something that we do to the law; it is also something that the law does to us. Rational reconstruction is a form of vulnerability; it is the occasion for a certain type of hermeneutical power over the individual. Thus, the study of subjectivity is important to the study of jurisprudence because the act of legal understanding affects the legal subject in ways that standard jurisprudential accounts do not contemplate. ${ }^{91}$

When we attempt to understand legal norms so that we can apply them to specific situations, we must begin with the presumption that they make sense-that they represent an intelligible and defensible scheme of regulation. We must bring an attitude of openness and acceptance to the object of our interpretation. Obviously, we may later criticize the law for making arbitrary and unjust distinctions. Nevertheless, if our goal is not critique but application-if we seek to understand doctrines so that we can apply them to

90. Of course, people may apply this assumption less stringently where the academic proposes a new statute or administrative regulation.

91. Here I focus only on the power over the self created by one particular form of legal understanding-rational reconstruction. That is because my subject is legal coherence. I do not mean to suggest that power over the self does not occur through the various other forms of legal understanding. I believe that it does, but that question is beyond the scope of the present Article. 
a concrete factual situation, an assumption of coherence becomes necessary as a test of our understanding. If legal norms make no sense to us, if they make distinctions that seem incoherent or arbitrary, this may be the result either of a lack of coherence in the norms themselves or of our failure to grasp the reasons that lie behind them and the correct manner of their application. If we do not assume that the legal norms we are trying to understand are coherent, we will have no way of determining whether our conclusions are due to a failure of our own understanding. Moreover, our debates about whether we have applied particular doctrines correctly will necessarily be waged against a background assumption of normative coherence. An interpretation of how a doctrine should be applied will be suspect if it makes the regulatory scheme seem more arbitrary or incoherent.

Hans-Georg Gadamer has argued that this attitude of interpretive openness and acceptance is central to all understanding. ${ }^{92}$ Gadamer purports to offer a unitary theory of cultural understanding, a position I have argued against repeatedly in this Article. In fact, his account of legal hermeneutics best suits the application of legal norms through rational reconstruction, in contrast to the many other types of legal understanding. This is not surprising, given that Gadamer devotes the majority of his discussion of legal hermeneutics to application of laws by a judge, and sees other forms of legal understanding as special cases of this type of application. ${ }^{93}$ Nevertheless, as long as we recognize the limitations of Gadamer's unitary approach to understanding, he sheds considerable light on the specific form of understanding called rational reconstruction. Indeed, what is most important about his theory, and what separates it from most Anglo-American jurisprudential accounts, is its recognition that the act of understanding affects the subject as well as the object of interpretation.

Gadamer calls the attitude of openness towards the object of interpretation the "anticipation of completion"; 94 it is the assumption of the coherence of the object of interpretation. He argues that this requirement follows from the traditional conception of the hermeneutic circle through which we revise our interpretations: we revise our understanding of what the parts of a text mean

92. GADAMER, supra note 50, at 261. Gadamer's reception in the American legal academy has been surprisingly slow. William Eskridge and Francis Mootz have been among the foremost exponents of his views. See generally William N. Eskridge, Jr. \& Phillip P. Frickey, Statutory Interpretation as Practical Reasoning, 42 STAN. L. REv. 321 (1990); William N. Eskridge, Jr., Gadamer/Statutory Interpretation, 90 Colum. L. REV. 609 (1990); Francis J. Mootz, III, The Ontological Basis of Legal Hermeneutics: A Proposed Model of Inquiry Based on the Work of Gadamer, Habermas, and Ricoeur, 68 B.U. L. REV. 523 (1988); Francis J. Mootz, III, Hermeneutics and the Rule of Law: Why the Obvious is Plausible (1992) (unpublished manuscript, on file with author).

93. GADAMER, supra note 50, at 274-95. Hence my earlier criticisms of Dworkin's and other jurisprudential approaches apply equally to Gadamer's failure to recognize the plurality of forms of cultural understanding and his attempt to view cultural understanding as a single process. See supra Part III.C. It follows that I am equally critical of Gadamer's tendency to generalize about legal understanding per se; on this particular point his theory shares the same shortcomings as Dworkin's.

94. GADAMER, supra note 50, at 261. 
by considering their relation to the whole, and we revise our understanding of the meaning of the whole by considering its parts. ${ }^{95}$ Understanding is not possible unless we can revise our initial conception of an interpreted object. But revision is not possible unless we assume that the parts and the whole are related to each other consistently so that we can check our conclusions about one against our conclusions about the other ${ }^{96}$ In the context of legal rules, the anticipation of completion is an assumption not about logical consistency or narrative coherence of the law but about normative coherence. It is the assumption that the legal doctrines we are trying to understand and apply have reasons behind them and that these reasons (and choices among conflicting rationales) make sense.

One might object that applying legal norms only requires their intelligibility; we do not have to assume anything about the normative coherence of doctrines in order to apply them. However, Gadamer's point is that the form of understanding I call rational reconstruction requires us to go much further. He claims that when we attempt to understand a text we also seek to understand the "truth" expressed by the object of interpretation. ${ }^{97} \mathrm{We}$ must be open to the possibility that what it says is true and that it has something to teach us. Understanding is receptivity; it is the willingness to be confronted by what the text says and recognize it as possibly having more authority than our own judgments. ${ }^{98}$ This argument rests once again on the notion that understanding requires us to have a way of revising our beliefs about the object of interpretation and rejecting some interpretations as misinterpretations. Unless we are open to the possibility of the text's truth, we cannot be sure that our conclusions that the text is mistaken are the product of the text or our misunderstanding of it..$^{99}$

The hermeneutic claim that understanding requires receptivity to the truth in the object of interpretation has a special meaning for legal understanding. The "truth" that legal doctrines offer us is a truth about the appropriate forms of social regulation. To understand and apply a legal doctrine is to attempt to see its point about how social regulation should occur. The conclusion that understanding is an attempt to recognize the validity of legal norms may seem

95. Id. at 291 .

96. "[The] assumption of self-consistency ... provides a standard for keeping or discarding individual interpretations of the text's parts .... [I]f one denies that a given text is internally coherent from the start, one has no way of knowing whether its inconsistency is the fault of the text or one's understanding of it." GEORGIA WARNKE, GADAMER: HERMENEUTICS, TRADITION AND REASON 83 (1987). Moreover, Gadamer argues, the ability to revise is necessary for understanding to be more than the reiteration of our own prejudices. We bring the prejudices and background assumptions of our cultural tradition to all understanding, and we "are not able to separate in advance the productive prejudices that make understanding possible from the prejudices that hinder understanding and lead to misunderstandings." GADAMER, supra note 50 , at 263 . Thus, we must have a way of revising our understandings through interpretation, and we cannot do this without the assumption of coherence.

97. GADAMER, supra note 50, at 262.

98. Id.

99. WARNKE, supra note 96 , at 89 . 
surprising from a traditional positivist orientation that assumes that law need not be just to be law. One might think that a positivist conception requires or at least allows us to distance our own beliefs about justice from the content of the legal norms we study. The hermeneutical point is that even the positivist, when she comes to apply the law, cannot take so distanced an attitude. Her beliefs are implicated in the very act of understanding and application; to understand legal norms she must attempt to grasp the extent to which they promote just and valid aims.

Consider once again the distinctions in the law of owners and occupiers between trespassers, licensees, and invitees. Suppose that we are asked to learn these doctrines and to apply them in a series of concrete cases involving accidents on a defendant's property. Our ability to understand these distinctions is directly related to our ability to apply them. Conversely, our failure in understanding these concepts is precisely our failure in applying them; we do not understand them because we do not know how to apply them. ${ }^{100}$ However, the process of understanding these doctrines so that we can apply them requires us to take a certain attitude towards them. We must assume that the doctrines draw intelligible distinctions and similarities that it is our goal to discover. If we do not assume this, we cannot tell whether any difficulties we encounter in application are due to the fact that the distinctions are incoherent or are due to the fact that we have failed to grasp their point fully. Thus, the very act of application creates in us the urge to make sense of distinctions, to create conditions of intelligibility that are the result of our interaction with the legal texts we are applying.

Moreover, the application of legal norms requires us to grasp their possible validity as well as their intelligibility. In order to apply the distinction between invitees and licensees, for example, we must also attempt to see the point of this scheme of legal regulation..$^{101}$ We must try to grasp why someone would find this an acceptable and valuable regulatory distinction. To understand this is precisely to understand the point of the legal norm. If we do not try to understand why someone would find the norm an appropriate form of social regulation, we cannot be sure whether our puzzlement is due to the norm's moral incoherence or to our own failure of understanding.

The "point" of a legal doctrine is not necessarily a single thing. It may be a balance or combination of various purposes, policies, and principles that the doctrine seeks to further. We understand the doctrine when we grasp this combination of purposes, policies, and principles and how they are balanced against each other in specific situations. Obviously, different people may see

100. See Dennis M. Patterson, The Poverty of Interpretive Universalism and the Reconstruction of Legal Theory, 71 TEx. L. REV. (forthcoming 1993).

101. See id.; Dennis M. Patterson, Law's Pragmatism: Law as Practice \& Narrative, 76 VA. L. REv. 937 (1990) (arguing that to understand a legal doctrine is to understand its point, which is the same thing as knowing how to apply it). 
a different point to a particular legal doctrine. That is because when we try to imagine why a person might find the legal norm an acceptable type of regulation, we bring our own judgments about what is right and good and about how one should balance competing purposes, policies, and principles. Because our judgments about these matters may differ, so may our conclusions about the point of particular legal doctrines. However, this does not change the basic claim: our attempt to apply legal doctrines still requires us to consider how the norm might embody valid principles of regulation, even though we disagree with others about what those principles are and what balance the legal norm strikes between them. ${ }^{102}$ Moreover, what is most significant about our disagreement is the implicit terms of agreement through which it occurs. When we disagree about the proper application of a legal norm, we do not disagree about whether the legal norm is coherent; rather, we disagree about the point of a legal norm whose coherence we accept for purposes of our argument. We attack our opponent's theory about the point of the norm because it makes the legal norm less coherent from our perspective-because it misdescribes the purposes, policies, and principles underlying the doctrine, or balances them in an unconvincing or arbitrary way. When application is at issue, we place ourselves "on the side" of the legal norm, defending it from those who would apply it improperly.

Our previous discussion has emphasized that understanding the "why" of law (that is, why the law makes the distinctions it does) and the "how" of law (that is, how to apply law) are inseparably linked. Understanding is application; to understand is to be able to apply. This is the central insight of Gadamer's discussion of legal hermeneutics. ${ }^{103}$ Indeed, Gadamer claims that this connection between understanding and application underlies all hermeneutical activity; it is the source of his provocative claim that legal hermeneutics is the paradigmatic case of interpretation and understanding. ${ }^{104}$

The requirement of openness to the truth of legal doctrines is perhaps easiest to see in the context of learning or teaching legal rules. Suppose that

102. This is in accord with the earlier discussion of rational reconstruction, see supra Parts II.C \& III.D.1. There I argued that because the question of what is a bona fide moral principle depends on our preexisting political and moral commitments, individuals may disagree about whether the same body of doctrine is rationally reconstructible. Our experience of legal coherence inevitably depends upon the conception of actual justification we bring to legal understanding.

103. GADAMER, supra note 50, at 294 ("It is the work of interpretation to make the law concrete in each specific case, ie [sic] it is the work of application.") (footnote omitted).

104. Id. at 277 ("[W] have the task of redefining the hermeneutics of the human sciences in terms of legal and theological hermeneutics."); id. at 289 (discussing "the exemplary significance of legal hermeneutics"); id. at 292 ("Legal hermeneutics is able to point out what the real procedure of the human sciences is. Here we have the model for the relationship between past and present that we are seeking."); $i d$. at 293 ("Legal hermeneutics is . . no special case but is, on the contrary, fitted to restore the full scope of the hermeneutical problem and so to retrieve the former unity of hermeneutics."). It is important to recognize, however, that this claim is motivated by Gadamer's mistaken assumption that rational reconstruction by a judge is the central case of legal understanding. Although $I$ have argued against that view in this Article, his insight into the process of rational reconstruction remains quite valuable. 
we wish to understand the doctrines of owner-occupier liability. We can memorize the elements of these doctrines, but we do not truly understand them until we can apply them. We cannot apply them until we understand the purposes the doctrines serve. And we cannot understand the purposes the doctrines serve until we attempt to see why they make sense as a scheme of social regulation. We must employ this assumption as a necessary check on our mastery of legal materials. If we cannot imagine valid policies underlying a doctrine, we will find ourselves unable to explain what the contours of the doctrine should be. Thus, we cannot rest content with the conclusion that the doctrine as applied makes ridiculous or incomprehensible demands. If it does, perhaps that means that we do not fully understand the doctrine.

The experience of the first-year law student confirms that puzzlement about the content of a doctrine often results from uncertainty about its application in concrete circumstances. The student is perplexed because the bare words of the doctrine might be applied in any number of different ways. When I explain to my torts students that the theory of res ipsa loquitur requires that the accident that occurred be unlikely to occur in the absence of negligence, they are sometimes puzzled as to when this is the case. They do not understand how to apply the doctrine; they lack the know-how or "situation sense"105 of a lawyer who understands the rules. I then have them consider a series of hypotheticals in which particular accidents occur and ask them whether they believe that the doctrinal test has been met. In making these judgments, they must develop a conception of why one would allow a res ipsa case to go to the jury. To do this, they must understand why the doctrine makes sense as a scheme of human regulation. Hence, they imagine policies that stress the need to compensate innocent plaintiffs, the need to "smoke out" information from recalcitrant defendants, and so on. They then apply these theories to sort out the various factual situations as falling within or outside the doctrine. The act of understanding and applying these doctrines requires them at some level to accept the validity of these policies and their furtherance through the doctrine of res ipsa loquitur.

The conclusion that understanding legal norms requires us to seek to understand their validity will be most troubling in the context of laws that we believe to be unjust. For example, suppose that we believe that abortion is murder and we are asked to apply a statute that permits abortions to go forward after a statutorily prescribed waiting period. In applying this statute in close cases, we must attempt to understand not only why it makes sense to require a waiting period, but also why it makes sense to permit abortions to go forward after the waiting period is over. To use an earlier metaphor, we must

105. KARL N. Llewellyn, THE COMmON LAW Tradition 121 (1960); see also Dennis M. Patterson, Law's Practice, 90 Colum. L. Rev. 575, 591 (1990) (book review of KARL N. LlewellyN, THE CASE LAW SYSTEM IN AMERICA (1989)) ("Both Wittgenstein and Llewellyn look at understanding as a gradual process of initiation. ... [ [of finding] one's feet in the enterprise."). 
place ourselves "on the side" of the statute for purposes of our interpretation. Yet there is no doubt that individuals who believe that abortion is murder can understand and apply such a statute. Their understanding of the law's appropriate application may differ from the understanding of those who hold contrary views about abortion because in attempting to understand the point of the regulation, they bring a different set of values to bear and may reach different conclusions about the appropriate balance among the purposes the regulation is designed to serve. For example, an opponent of abortion may emphasize the need to ensure that choice is fully informed and that the physical and emotional consequences of abortion are fully understood by the mother; hence, she may apply the regulation strictly so as to limit the number of cases in which abortions may proceed. Nevertheless, even a committed opponent of abortion, in order to understand and apply the waiting period requirement, must attempt to see how it makes sense as a scheme of human regulation. Our ability to understand the validity of even those norms with which we strongly disagree is essential to our understanding of their proper application.

I have emphasized that understanding legal norms for the purpose of rational reconstruction requires an attempt to make legal distinctions intelligible and to grasp their validity. However, not all attempts are successful. On occasion, we may conclude after considerable effort that a particular distinction. makes no sense at all; we simply do not understand how it can be applied coherently. This conclusion indicates that we have given up the quest for understanding for the purpose of application. We must retreat to other forms of understanding, for example, to understanding the political or sociological factors that lead others to make decisions using the doctrine. Nevertheless, the issue of application may arise in a new context. We may say that our interest lies not in applying the law, but only in predicting how others will apply it. Yet even here the act of understanding another's actions may implicate our own ability to apply the law. It will be difficult indeed to explain why another person applies the law in certain circumstances if we cannot make sense of the reasons she believes to underlie the law. If she sees legal norms as intelligible and grasps their validity, our explanation of her behavior may require us to understand the law on those terms. Hence, we have not fully surrendered the attempt to understand how to apply the law. Only if we regarded it not as a norm guiding human action but as a mere stimulus that created a predictable response would we truly have abandoned the attempt to make the legal norm intelligible as a norm. ${ }^{106}$

106. The legal realist Herman Oliphant's theory of stare decisis took precisely this approach. See Herman Oliphant, A Return to Stare Decisis, 14 A.B.A. J. 71 (1928). Oliphant argued that facts should be considered stimuli which produce a doctrinal result in a particular judge. The goal of legal studies was to record precisely which stimuli produced which results in a particular case; only then could one understand the practical meaning of legal doctrines. Oliphant's theory was attacked both by opponents and sympathetic 
This discussion suggests that we must consider the type of understanding I call rational reconstruction in a new light. Our attempt rationally to reconstruct the law is an act of understanding and application that brings the assumption of completion to legal materials. It is an attempt not only to see the law as a consistent set of norms but also to understand the "truth" inscribed in the law. It involves a receptivity to the validity of the policies that underlie legal doctrine. It requires us to be open to the possibility that the law actually has something to teach us about the proper forms of human association, the limits of human freedom, and the contours of human nature. It entreats us to consider the possibility that the law has more authority on the question of regulation of a particular area of social life than we do ourselves. It asks us to assume that the rules are the way they are for a good reason and that it is our job to find out what that good reason is. It hopes to see the law as the emanation of reason-not just the formal and barren reason of mere logical consistency, but a full-blooded substantive conception of reason suited to the demands of practical affairs.

The dominant metaphors in this hermeneutical conception are openness, receptivity, and submission to the constructed object of interpretation. Indeed, Gadamer suggests that understanding is partly a surrender to the possibility of truth of the text. ${ }^{107}$ When we truly understand, our understanding will result in a change of our attitudes in response to the truth of the text that we understand. This alteration of our own beliefs in response to hermeneutic activity is part of what Gadamer calls the "fusion of horizons."108 We approach the text-as-we-interpret-it by revising our own beliefs as much as we make the text approach us through our interpretation of it. ${ }^{109}$

critics of Legal Realism on the grounds that one would also need to take into account a judge's understanding of the doctrinal context and the purpose of legal doctrines in order to predict how a judge would be affected by factual "stimuli." Hence, even Oliphant's behaviorist model required understanding the point of legal norms from the perspective of the judge or legal decisionmaker. See, e.g., Morris R. Cohen, Justice Holmes and the Nature of Law, 31 ColuM. L. REv. 352, 366 (1931).

We can restate Cohen's point in terms of our earlier discussion of the plurality of forms of legal understanding. Understanding the law for the purpose of prediction may require us to employ some aspects of rational reconstruction. These forms of understanding are mutually dependent as well as differentiated. Although Gadamer (and Dworkin) would see in this example proof that all legal understanding is ultimately parasitic on rational reconstruction, this example actually demonstrates the overlapping nature of the various forms of legal understanding.

107. GADAMER, supra note 50 , at 262 .

108. Id. at 273 .

109. Id. at 272-73. Gadamer's theory of interpretation is posed against an older conception of hermeneutics that at first seems intuitively more plausible. This view assumes that the purpose of interpretation is to try to understand the meaning of a text as an expression of the past or of an alien culture, but not to reach agreement with it. This conception is neutral with respect to truth; the meaning of the interpreted object does not depend upon its truth or falsity to us. Gadamer rejects this approach as offering only a half-measure towards real interpretation and real understanding. It is like having a conversation with someone only to get to know them but not to learn anything from them or reach any sort of agreement with them. Id. at 270 . Indeed, he argues that there is a certain close-mindedness to this sort of hermeneutical inquiry: "By including from the beginning the other person's standpoint in what he is saying to us, we are making our own standpoint safely unattainable." Id. By limiting the focus of our inquiry, we do not allow the other person (or the text) to challenge our beliefs; we may even enjoy the 
Behind Gadamer's theory is an idea borrowed from Heidegger: interpretation is existential as well as intellectual. ${ }^{110}$ Interpretation is not just something that we do to the objects we interpret; it is something that happens to us. To interpret is to be called, to be challenged or summoned. "Understanding begins," Gadamer tells us, "when something addresses us. This is the primary hermeneutical condition." "That is why we are not wholly safe when we interpret. To understand is not, as some might think, to study the object of interpretation at a distance, free from its claims upon us. It is above all to be challenged, to be vulnerable to the alteration of our own beliefs through the fusion of horizons. To risk understanding is to risk change.

Thus, Gadamer's theory is above all an existential theory of interpretation. It associates the nature of human understanding with the conditions of human existence, and it emphasizes the effects that human understanding has over human lives. However, it should not be confused with the vision of a radically free subject associated with Sartrean existentialism. Quite the contrary; the Gadamerian subject is the product of her cultural moment. She is thoroughly culturally constructed; she cannot shed her fore-understandings and prejudices by an act of will. ${ }^{112}$ And yet her acts of interpretation will undoubtedly affect her life, for to risk interpretation is necessarily to risk alteration of one's own beliefs. Yet this risk is not one she can easily avoid. The urge to understand is part of the human condition. We might even call this the "will to understand." But unlike Nietzsche's "will to power," the will to understand is not a celebration of human domination. The urge to understand is an urge towards a certain type of vulnerability.

\section{B. Coherence and Co-optation}

Gadamer offers his ontological account of understanding as a theory of how understanding can be successful; agreement with the constructed object of interpretation is a means towards truth. Nevertheless, my interest is in the ideological component of understanding. Therefore $\mathrm{I}$ am as interested in how interpretation can go badly as in how it can go well. Here I part company with Gadamer, for his own theory shows how interpretation can be fraught with peril. Although I agree with his ontological explanation of understanding, I

superiority of believing that we are explaining the person's beliefs or the text's arguments as the effects of historical structures or social forces rather than as claims to truth with which we must grapple.

110. MARTIN HEIDEgGER, BEING AND TIME 191-95 (John Macquartie \& Edward Robinson trans., 1962). Hence, this approach to hermeneutics is also called "ontological." (Ontology is the study of being.) Like many philosophers in the Continental tradition, Gadamer and Heidegger believe that there is something special about human being, and the relationship between human existence (the human condition) and understanding is the subject of ontological hermeneutics.

111. GADAMER, supra note 50, at 266.

112. Id. at $267-68$. 
believe that it also demonstrates how particular problems of understanding occur.

There are two symmetrical ideological difficulties that flow from the ontological basis of understanding. The first stems from our historical and cultural situation. When we attempt to understand a text or any cultural artifact, we impose upon it a set of preconceptions that arise from our cultural and historical location as well as our own practical concerns. ${ }^{113}$ These "foreunderstandings" or "prejudices," as Gadamer calls them, ${ }^{114}$ are not merely subjective creations of the individual-we are not fully in control of the cultural tradition in which we live and that shapes our horizons of understanding. ${ }^{115}$ What we interpret therefore is always the text-as-weunderstand-it, conditioned by our historical and cultural situation. We attempt to reach agreement between ourselves and the text-as-we-understand-it, but the latter is already the result of our own fore-understandings. ${ }^{116}$ Hence, Gadamer claims, "[u]nderstanding . . . is always the fusion of these horizons which we imagine to exist by themselves." 117

Understanding, then, is a negotiation between our own understandings and the object of understanding we construct from them. However, if both we and the constructed object of our interpretation reflect our fore-understandings and prejudices, agreement between ourselves and the text may be altogether too easy to reach. "Interpretation" will simply mean the reinforcement of existing prejudices already located in ourselves and in the constructed object of our contemplation. ${ }^{118}$ We will simply comprehend the interpreted object so that it is too easy to reach agreement with it. Our interpretation results in little more than the continuous reaffirmation of our existing beliefs and traditions. It is like attending a meeting of fellow ideologues where we are pleasantly surprised to discover that everyone agrees with us.

The second ideological difficulty stems from the vulnerability inherent in understanding - the way that the object of interpretation challenges us with its claims to truth. If understanding entails a quest for agreement with what we

113. Id. at 270-73. The anticipation of completion is an example of such a prejudgment, one which Gadamer insists we always bring to a text. $l d$. at 261 .

114. Id. at $237,240,245-46,261$.

115. Gadamer calls this phenomenon "effective-history." See id. at 267-69. It is the force of history over those who belong to a tradition, "so that even in rejecting or reacting to [a tradition we] remain conditioned by it." WARNKE, supra note 96 , at 79 .

116. GADAMER, supra note 50, at 263-64.

117. $I d$. at 273 . This is another way of saying that we cannot fully separate the subject of interpretation (the interpreter) from the object of interpretation (the text-as-we-understand-it).

118. Because Gadamer does not seek a theory of ideological effects in understanding but a theory of how truth is achieved, this presents a problem for his theory of understanding and leads to the familiar charge that Gadamer's account of understanding results in historical or cultural relativism. See, e.g., THOMAS K. SEUNG, STRUCTURALISM AND HERMENEUTICS 204-12 (1982). This is not a difficulty for my use of hermeneutical theory because I am specifically interested in how the ontological basis of understanding leads to particular ideological effects. Thus, I agree with Gadamer about the mechanisms of understanding but disagree about the consequences of these mechanisms. 
interpret, perhaps we will be seduced into agreeing with the wrong things. Understanding puts our norms and values at risk of change, but we have no guarantee that the change will not be for the worse. Our need to reach agreement may result only in our co-optation. ${ }^{119}$ This fear underlies our hesitation in acknowledging Gadamer's claim that understanding is acceptance of a text's claims to truth. Gadamer tells us that to risk understanding is to risk consensus, but to risk consensus is to risk complicity. Indeed, this possibility is chillingly suggested in the closing pages of Truth and Method:

$[\mathrm{U}]$ nderstanding is not playing, in the sense that the person understanding holds himself back playfully and withholds a committed attitude to the claim that is made upon him. The freedom of selfpossession necessary to be able to withhold oneself in this way is not given here. ... Someone who understands is already drawn into an event through which meaning asserts itself. . . . When we understand a text, what is meaningful in it charms us just as the beautiful charms us. It has asserted itself and charmed us before we can come to ourselves and be in a position to test the claim to meaning that it makes. ... In understanding we are drawn into an event of truth and arrive, as it were, too late, if we want to know what we ought to believe. ${ }^{120}$

119. Once again, because Gadamer does not offer a theory of the varieties of ideological thinking but a theory of how true understanding is possible, the corresponding difficulty for his project is knowing when we must cease our efforts at understanding. Thus, when we read a text that advocates evil or unjust things, must we try to discover its truth to understand it? Does a proper understanding of Mein Kampf, for example, require us to acknowledge the possible truth of Aryan supremacy? See WARNKE, supra note 96, at 90 . Gadamer concedes that some texts will be so distant from our cultural horizon and our moral values that we can learn nothing from them; at most we can try to explain them as the product of historical forces or psychological causes. However, as Warnke points out, Gadamer does not tell us how to distinguish these texts from texts that can truly teach us something; he does not tell us when one is "supposed to give up the attempt to learn from one's object [of interpretation]." Id. at 89. Thus, she asks, "Is there not a danger here that, if we do not simply misinterpret works so that they comply with our own beliefs, we will end up learning from truth-claims we ought long ago to have dismissed?" Id. at 89-90. Wanke's criticism of Gadamer's claims to true understanding leads directly to my concern with the problem of co-optation.

120. GADAMER, supra note 50, at 446 . Gadamer might respond by distinguishing among the various forms of agreement we can have with a text. We can confront the possible truth of a text in several ways. The most obvious way is to accept what we read as true and adopt it as our own. But we need not do so. We may recognize that there are elements of the text that are true or partly true and others that we must reject. Yet confrontation with the text will compel us to develop counterarguments. In that case, we do not accept the text as true, but we have allowed the text to affect us nevertheless. When we critique another's position, our critique is necessarily situated by the position we criticize. Thus, Gadamer might argue in a Hegelian manner that we may learn something from evil even when we reject it, for by having to confront what we reject, we incorporate that experience into our lives and thereby gain a greater wisdom. Our encounter with racist literature may lead us to a greater understanding of ethnic tensions and bring us to reassert our beliefs in racial and religious tolerance all the more strongly while understanding our position all the more deeply. If so, our understanding of ethnic equality will owe something to the analysis we find in racist literature. Because we confronted these arguments on their own terms, our encounter will be more than a disdainful explanation of a text by reference to historical forces or psychological motivation.

Sympathetic critics of Gadamer like Paul Ricoeur and Georgia Warnke have suggested just such a critical hermeneutic approach. PAUL RICOEUR, HERMENEUTICS AND THE HUMAN SCIENCES 89-100 (1981); WARNKE, supra note 96, at 106 . Unfortunately, Gadamer himself often appears to embrace the most cooptive features of interpretation as exemplified in the final paragraphs of Truth and Method quoted above. As Warnke notes, "Gadamer at times seems to suggest that the consensus with the object or the tradition 
Thus the existential account of understanding presents two symmetrical problems: that we will too easily conform the interpreted object to match our preexisting beliefs and that we will too easily tailor our beliefs to match the interpreted object. Let us call the first the problem of conformation and the second the problem of co-optation. If ontological hermeneutics reveals the existential basis of understanding, it equally demonstrates the kinds of errors and delusions that can result from the urge to understand. Its account of how interpretation is possible also demonstrates how the urge to interpret-the will to understand-may lead to conformation, collusion, or co-optation. Ontological hermeneutics unwittingly reveals to us the Faustian bargain of understanding, where we gain comprehension at the expense of a larger complacence and complicity.

If, as Gadamer claims, legal understanding is the paradigm of all understanding, these twin ideological effects are also effects in legal understanding. Thus, there is a danger that when we attempt to understand the law, either we will too easily find the law to conform to our own political and moral beliefs or too easily conform our own political and moral beliefs to those of the law as we understand it. Such ideological effects need not occur in every case of legal understanding. Nevertheless, we must be open to the possibility that they can occur and that they may deeply affect our judgments about legal coherence.

I have discussed the problem of hermeneutic conformation at length elsewhere; ${ }^{121}$ here I wish to note only how the problem throws a somewhat different light on the effects of ideology on legal decisionmaking. Accounts of judicial decisionmaking often assume the model of a "rogue" judge whose ideology tempts her to stray from the law and who must therefore be constrained by objective legal rules that prevent her from doing what she wants to do. However, if my account of legal understanding is correct, the problem may be quite different. The danger of hermeneutic conformation is that when (for example) a liberal judge looks at the law, she already sees liberal principles emanating from it and understands deviations from these principles as exceptional cases or simply mistakes. Such a judge is not actively inserting her own private policy preferences into the law; she simply sees the law as being that way. ${ }^{122}$ The phenomenon of hermeneutic conformation explains

is substantive in that it issues in just such a concrete agreement" between ourselves and the text we attempt to understand. Id. at 107-08. Under these circumstances, horizon fusion "mean[s] that there is no longer any difference between our position and that of the object; understanding involves finding a way to agree ... and hence ignoring the possible necessity of criticizing the text or text-analogue under study." Id. at 108.

121. See Balkin, Ideology as Constraint, supra note 4; J.M. Balkin, Taking Ideology Seriously: Ronald Dworkin and the CLS Critique, 55 UMKC L. REv. 392 (1987) [hereinafter Balkin, Taking Ideology Seriously].

122. Hence, it follows that the important jurisprudential problem is not explaining how law external to individual consciousness can be objective so that it can constrain the dreaded "rogue judge." The problem is not the "rogue judge" who must be kept from inserting her private and personal prejudices into 
why liberal and conservative judges can in good faith see quite different principles emanating from the same body of law. Both believe that they understand the point of legal doctrine and how best to continue it, but both come to different conclusions because the constructed object of interpretation-the law as they understand it-readily conforms to their respective beliefs. The law seems coherent to them because it readily matches their political and moral judgments.

Equally important is the problem of hermeneutic co-optation. Our need to make the law make sense so that we can apply it may lead to changes in our own beliefs that facilitate our conclusion that the law is coherent. In other words, the very activity of rational reconstruction may co-opt us in ways of which we are wholly unaware even if we still disagree with significant portions of settled doctrine. Rational reconstruction is not simply a game that places no demands on us, that leaves us untouched, that affects us only in ways we can put aside at will. If law is truly an interpretive practice and interpretation is ontological, we always risk change through our acts of legal interpretation.

As lawyers we learn and practice the skills of rationally reconstructing diverse groups of precedents and doctrines. It is surely possible that we can separate this act of creating coherence from our own well-considered judgments about a particular area of social regulation. Yet it is also possible that if we have no well-defined beliefs about a particular subject before we begin this process, we will find it easy enough to adopt the work of rational reconstruction for ourselves. The act of understanding requires us to risk complicity with what we understand. It would be miraculous indeed if such risks never came to fruition.

Perhaps the most obvious example of how hermeneutic co-optation might occur involves legal education. Law students come to the study of law with only the vaguest notions of the structure of the legal system and the content of legal norms; they are unlikely to have seriously considered possible conflicts of value between legal doctrines. Despite (or perhaps due to) their innocence, they also come with a presumption that they are to learn about a legal system that is basically coherent and just. Once engaged in the study of law, the law student accepts Gadamer's argument for the anticipation of completion with a vengeance: she sees every experience of legal incoherence as her own fault and not the fault of the system of doctrine she studies. She assumes that the doctrines she learns must make sense and that all failures of comprehension are those of her own understanding. She blames herself, not the object of her study.

law. Rather, the problem is the sincere judge, who is destined to see the law according to her own ideological perceptions and beliefs. The difficulty is not one of unconstrained freedom but one of ideological determinism. This argument is made at greater length in Balkin, Ideology as Constraint, supra note 4. 
The law student, after all, has come to law school to understand law. Her social existence is wrapped up in the enterprise of understanding. Much rides on her ability to make sense of legal norms and to apply them both in the classroom and on examinations. Given these needs, she will turn all her efforts to the task of understanding the law and to forging an agreement between her own views and those of the constructed object of her understanding. She will strive to recognize not only the intelligibility of legal distinctions but also their claim to validity. Here the possibility of co-optation is very strong. If, as ontological hermeneutics tells us, understanding is a kind of vulnerability and receptivity, few are more vulnerable and receptive than the frightened first-year law student, whose goal is less to ask whether legal doctrines make sense than to grasp why they do so. If understanding is openness to the possibility that the law has greater authority about matters of social regulation than our own views, few are more open than the initiate in legal education, who seeks more to clarify legal authorities than to contest them. The act of learning the law creates great pressures on her to adopt the reason of the law as her own reason, simply because so much turns on her ability to apply the law and meet the requirements of professional credentialization.

The question of hermeneutic co-optation connects with our earlier discussion of cognitive dissonance. I argued previously that there was no reason to expect that the need to reduce cognitive dissonance would result in alteration of an individual's beliefs and attitudes about legal coherence unless an individual had a stake in the coherence of the legal system or its parts. However, the act of rational reconstruction may itself create such a stake in the coherence of what we attempt to reconstruct. This is the unanticipated corollary of Ronald Dworkin's well-known claim that disagreements about law are not semantic but interpretive because knowledge of law is interpretive. ${ }^{123}$ If disagreements about law are interpretive, we may have a personal stake in our interpretations because our reconstruction of the law has produced an agreement between ourselves and the constructed object of interpretation. Our interpretations-which include our work at rational reconstruction-have become part of our beliefs, and our own sense of self-worth may depend upon their acceptance and success.

I noted earlier that compensating lawyers for taking positions contrary to their beliefs does not by itself produce a need to reduce cognitive dissonance. Hermeneutic co-optation suggests a more subtle explanation of the ideological pressures on lawyers. The problem is not so much that lawyers are paid to believe things; it is that they are paid to understand things. Lawyers must make sense of the law and argue for legal positions as the best continuation of legal materials. They are required, in other words, to reach a certain type of agreement between themselves and the object they study in order to make

123. DwORKIN, supra note 8 , at 87 . 
sense of the law and to persuade others. Such a task cannot leave their beliefs wholly unaffected. If I am asked to give an account of existing legal doctrine, even of doctrines I do not believe in, I often find that in the heat of argument, the position I am defending seems increasingly sensible to me. I become convinced of it precisely because it is necessary for me to make it coherent in order to defend it. In the classroom, one of the best ways to make students see the other side of an argument is to ask them to defend that position against another member of the class. Because they gain a momentary personal stake in arguing their position effectively, they will work to make the position they defend coherent, and thus they will begin to see the truth of the moral distinctions that the position draws.

The ontological account of understanding suggests that hermeneutic cooptation can exist in the absence of economic incentives for conformity of belief. Instead, changes in our beliefs may result from our desire to understand. This picture of legal understanding is quite alien to the traditional picture of the lawyer masterfully manipulating legal doctrines in order to achieve some set of preexisting goals. It argues instead that lawyers are shaped by as well as shape law, that they are changed by law as much as they seek to change it.

Although we may find the image of the clever lawyer manipulating the law distasteful to our beliefs about the rule of law, there is simultaneously something quite comforting in this picture. The clever lawyer seems to be in control of her interpretive situation. She chooses the arguments that she makes about the law; she employs legal doctrine to serve her chosen ends. The very idea of manipulation implies that she is distanced from the act of legal interpretation: legal argument is merely a game that she can begin or end at will, with no consequences for her beliefs, attitudes, or sense of self. This instrumentalist conception of law imagines that the law is a tool that can be picked up or put down at will, an inert element that is not part of us but one that we employ to serve our preexisting values and ends.

The comfort in this picture is the comfort of believing that we are in control of our beliefs and attitudes. Yet the picture of the masterful, manipulating lawyer is quite false. It is false not because of objective constraints in legal doctrines that prevent lawyers from doing what they seek to do, but because it relies on a picture of an individual who can stand apart from her acts of understanding and argument, who is not already affected, transformed, and on occasion even consumed by them. It is false because the tools of legal understanding are not like hammers or pliers that can be picked up or put down at will. Through acts of understanding, these tools have become part of us. They have become like our eyes and limbs, tools that we do not merely use but that also constitute us.

The illusion of legal instrumentalism is also its consolation - the belief that the tools of legal understanding remain separated from us when we engage in legal understanding, that we are unaffected, that we are free. Thus the vision 
of the rogue lawyer, like the rogue judge, comforts us because it preserves our belief in our hermeneutic autonomy. Our comfort in this belief is itself an ideological phenomenon worthy of study.

\section{Legal Understanding as a Form of Power}

I have emphasized the possibility of hermeneutic co-optation not because I believe that it occurs in all cases of legal understanding. It does not. I emphasize it because it illustrates a larger point. Legal understanding is not the passive reception of an inert object by a consciousness untouched by the act of understanding. Rather, legal understanding, like all understanding, affects our beliefs and our lives. It is something that we do to the object of interpretation, and something that the constructed object does to us. Our freedom from the object of interpretation is not unconditionally given. Understanding happens, and it happens to us. Hermeneutic co-optation is perhaps the most extreme case of this phenomenon, but even when there is no co-optation, understanding always changes us, however slightly. We become, to some degree, different individuals because of our acts of understanding. It is commonplace to say that our experiences have shaped us and changed us. I simply wish to add that legal understanding is such an experience. It is not merely the distanced recognition of a preexisting pattern or property. Legal understanding is the occasion for the power that legal ideas have over us.

The ontological account of legal understanding offers us a different account of ideological power. A recurring difficulty in theories of ideology has been to explain how ideas can have power over individuals. ${ }^{124}$ The ontological theory of understanding shows how this is possible. Ideological power is a special case of the power that derives from the tools of understanding that we use to express our values and make sense of the social world. The power of ideology is precisely the power that the tools of our understanding have over us. We need tools of understanding to make sense of the world, but, like our limbs and eyes, these tools become part of us. Those who shape or control the tools of our understanding have a certain power over us because we are, to a large degree, the tools of our own understanding. ${ }^{125}$

In this way understanding, and in particular legal understanding, makes every subject the locus of a certain type of power: the power that arises from

124. Cf. JOHN B. THOMPSON, STUDIES IN THE THEORY OF IDEOLOGY 130-31 (1984) (noting that for various thinkers ideology "bears no intrinsic connection to the problem of domination" and arguing that the study of ideology must become the "study [of] the ways in which meaning (signification) serves to sustain relations of domination.") (emphasis omitted).

125. I mean this in two different senses. Human beings are, in large part, their own "cultural software"-their modes of understanding make them who they are as individuals. Thus, the tools of our understanding constitute us as individuals. At the same time, we are "tools" of our understanding in the sense that our acts of understanding and the conditions of our understanding direct us in particular ways, revealing some possibilities while obscuring or foreclosing others. 
the forms and limits of the tools of our understanding. These constitute what I earlier called "cultural software"- the modes and methods of understanding that become part of us and shape the way that we perceive the legal and social world. To understand is to employ existing tools of understanding to create new ones or adapt old ones and, in the process, to be changed. Hence it is to be the locus and the occasion of a certain form of hermeneutic power. The phenomenon I have called hermeneutic co-optation is merely an extreme case of this power, but it exists, if only to a minor degree, in every act of understanding.

The ontological basis of legal hermeneutics at last reveals its cratological ${ }^{126}$ aspect-the connections between understanding and power. These connections have been virtually ignored by standard jurisprudential accounts despite jurisprudence's recent turn to interpretation. Indeed, this turn is naive if it fails to grasp the connections between interpretation, understanding, and ideological power over the individual who understands the law.

This neglect is evident in Ronald Dworkin's interpretive theory of law as integrity. Dworkin has emphasized the interpretive nature of legal knowledge while steadfastly refusing to consider the sociological and ideological implications of legal understanding, arguing that such analyses are "external" accounts that can have no effect on the proper internal perspective of legal understanding. ${ }^{127} \mathrm{By}$ ignoring the contribution of the subject to the nature of legal understanding, Dworkin's theory neglects the twin difficulties of hermeneutic conformation and hermeneutic co-optation. In a previous work, I have stressed the problem of conformation: Dworkin does not account for the possibility that decisionmakers who believe in good faith that they are continuing and not altering the law may easily find that the law conforms to their own political beliefs because individuals with different political perspectives often see different principles emanating from the same legal doctrines. ${ }^{128}$ Dworkin's theory must, but cannot, distinguish good-faith subjective interpretation of the law from what he would dismiss as ideological bias. The difficulty is that both feel exactly the same to the individual interpreter of the law, who is the focus and ultimate arbiter of Dworkin's internal perspective. The problem of conformation arises directly from Dworkin's refusal to make the jurisprudential subject a subject of jurisprudence.

Now I would like to suggest that there is an equal and opposite difficulty for Dworkin-not the problem of hermeneutic conformation but that of cooptation. The difficulty is not that the law as we see it will too easily seem to

126. By "cratology," I mean the study of power in its various forms and usages. See J.G. MERQUIOR, FoucAulT 108, 113-14 (1985) (defining cratology as the theory of power).

127. See supra note 10 and accompanying text.

128. See Balkin, Taking Ideology Seriously, supra note 121. 
match our political convictions, but that the pressure to reduce cognitive dissonance and the urge to make sense of legal norms may make it too easy for us to match our moral and political convictions to the law as we see it. The danger is not that we will fail to see the law as coherent, but that we will not fail in our attempt-that through our efforts to understand and our eagerness to make sense, we will too readily accept the similarities and the distinctions the law offers us as coherent. We will come to believe that the balances have all been struck rightly and that all doctrinal conflicts have disappeared.

Dworkin closes Law's Empire with an optimistic recapitulation of the old saying that "the law works itself pure." 229 Not surprisingly, this expression disguises the contributions of the subject of interpretation by ascribing an emerging purity to the object of interpretation-the law. To understand the ideological difficulty in Dworkin's project, we might approach the matter from the standpoint of the subject: Does the law seem pure because it is pure or because we have become accustomed to its sullied colors? If we work the law pure, does not the law also work upon us, and in the process may not our very notions of purity themselves become impure? When we enter a room with a stench, a few minutes later our sensory apparatus normalizes itself, and we no longer notice the foulness entering our nostrils. Is this how the law works itself pure? If the subject is placed beyond scrutiny, how can we tell?

This defect in Dworkin's account of legal understanding stems from its failure to grasp the cratological aspects of legal understanding - the power that legal understanding has over us. It fails to see legal understanding as the occasion for self-transformation. ${ }^{130}$ It thus allows us to ignore the ways in which our social situation affects our understanding and our understanding affects the properties of the legal system we understand.

For me, this is the most troubling ideological aspect of a theory of interpretation that pretends that ideology is irrelevant to jurisprudence. In

129. DWORKIN, supra note 8 , at 400 .

130. This problem is symbolized by Dworkin's ideal judge, Hercules. The problem is not that Hercules is all-knowing and infinitely patient. It is rather that his interpretive situation is not truly human-he is a dispassionate, distanced, static ideal of understanding, wholly unaffected by the act of legal interpretation. Missing from this account is the subject's vulnerability to change through the hermeneutic encounter.

Ironically, the Greek mythological hero Herakles is a valuable corrective to Dworkin's distortion. The mythological hero becomes the object of adoration because of an act of struggle through which he is transformed. The hero's transformation represents and idealizes those facets of human life in which we are tested through trial and difficulty, undergo transformation through struggle and suffering, and come to understand our worthiness as individuals. Indeed, the importance of Herakles to the Greek and Roman world stemmed precisely from these features of his life; throughout the ancient world, hero cults of Herakles sprang up in which Herakles was portrayed as a Christ figure transformed by his labors, see G. KARL GALINSKY, THE HERAKLES THEME 4-6 (1972). On the hero cults of Herakles, see LeWIS R. FARNELL, GREEK HERO CULTS AND IDEAS OF IMMORTALITY 95-174 (1921). On the central importance of the mythological hero's struggle and transformation and its relation to conceptions of human life, see JOSEPH CAMPBELL, THE HERO WITH A THOUSAND FACES 30-38, 245-46 (2d ed. 1968).

A mythological hero like Herakles is a proper metaphor for legal understanding only if he undergoes change as the result of his encounter with the materials of the law. If, like Dworkin's Hercules, he is not affected by the act of interpretation, his understanding is not truly a human one. 
Law's Empire, Dworkin claims that normative coherence-or his equivalent, law as integrity-is an essential element of legal interpretation that we must postulate to explain our considered beliefs about legal interpretation. He compares the requirement of normative coherence to Neptune, a planet whose existence astronomers postulated before they discovered it. "They knew that only another planet, whose orbit lay beyond those already recognized, could explain the behavior of the nearer planets."131 Our demand that law appear principled to us, Dworkin argues, "suggest[s] another political ideal standing beside justice and fairness. Integrity is our Neptune."132

In astrology, Neptune has another meaning. It is the planet of selfdeception.

\section{CONClusion: Politics, PERSONIFICATION, AND the PRESERVATION OF INDIVIDUAL COHERENCE}

I began this Article by suggesting that the coherence of law is ultimately based upon the coherence of the world and that the coherence of the world is ultimately based upon the coherence of our selves. We have seen repeatedly how the attribution of features of the self to the objects of legal understanding makes the contributions of our subjectivity to legal understanding invisible. Yet this projection has always served a further and more basic purpose: it preserves and protects the coherence of the individual subject. By continuously projecting questions of coherence away from the self and onto the object of legal understanding, we avoid considering the coherence and incoherence of individual beliefs. We assume instead a coherent self who remains untouched by and unconnected to any normative incoherences that surround her in politics or culture and who has not already internalized cultural norms that are the product of historical accumulation, conflict, and compromise. The most common approaches to legal coherence implicitly rely on and preserve the coherence of individual belief, although they do so in quite different ways.

Consider once again Ronald Dworkin's approach to legal coherence. Dworkin argues that the law is coherent to the extent that it matches the beliefs of a single individual. In this strategy of "personification,"133 the requirement of legal coherence is the requirement that the law, like an individual, "speak with one voice." 134 Personification "attributes moral agency and responsibility" to the community; it "mean[s] that the community has its own principles it can itself honor or dishonor, that it can act in good or bad faith, with integrity or hypocritically, just as people can." ${ }^{135}$ Thus, the goal of legal

131. DWORKIN, supra note 8 , at 183.

132. Id.

133. Id. at 167 .

134. Id. at 165 .

135. Id. at 168 . 
interpretation is to see the law as the product of a single consciousness, and law may be criticized to the extent that it fails to match the coherence of a single individual's beliefs.

In contrast to Dworkin's approach is a claim made by many different scholars that legal coherence is impossible. It is made impossible because of "politics," by which is meant the play of interest groups in legislative and administrative action, and the many changes in judicial personnel over time. For these authors, it is as absurd to think that this assemblage of forces-often working at cross-purposes to each other-would create a coherent moral system of policies, principles, and purposes, as it is to believe that shuffling a deck of cards repeatedly would put them in a coherent order. Thus, Nigel Simmonds argues that because of politics, legal principles are "blunt[ed]."136 Andrew Altman contends that in a liberal society, law may not be amenable to rational reconstruction because liberal politics requires that the principles underlying law are always "truncated." 137 And Joseph Raz suggests that "[if] the law is meant to be taken as a system based on authority, its content is to be determined by reference to the intentions of legal authorities and their reasons, and, therefore, given the vagaries of politics, including ... judicial involvement in politics, there is no reason to expect the law to be

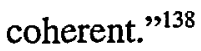

At first glance these two approaches could not be more at odds. One emphasizes how law can be seen as coherent by analogy to a person's beliefs, while the other denies the possibility of coherence because of the clash of personal wills involved in the creation of law. In fact, both employ a similar ideological strategy - both seek to demonstrate coherence or incoherence in the law through comparison or contrast with the beliefs of individuals, which are taken as the appropriate norm of coherence.

Dworkin, for example, bases his argument about the proper mode of legal interpretation on the metaphor of personification. ${ }^{139}$ Law is viewed correctly

136. N.E. Simmonds, Bluntness and Bricolage, in JURISPRUDENCE: CAMBRIDGE ESSAYS 1, 12 (Hyman Gross \& Ross Harrison eds., 1992).

137. Andrew Altman, Critical Legal Studies: A Liberal CritiQue 139, 145-47 (1990).

138. Raz, The Relevance of Coherence, supra note 13, at 295.

One of the most often quoted statements of this view is Roberto Unger's. Unger argues that "it would be strange if the results of a coherent, richly developed normative theory were to coincide with a major portion of any extended branch of law." For this to occur, Unger contends "[t]he many conflicts of interest and vision that lawmaking involves, fought out by countless minds and wills working at cross-purposes," would have to represent "an immanent moral rationality whose message could be articulated by a single cohesive theory." Unger accuses "the dominant legal theories" of believing in this possibility and hence attempting what he calls a "daring and implausible sanctification of the actual." Roberto $\mathrm{M}$. Unger, The Critical Legal Studies Movement, 96 HARV. L. REv. 563, 571 (1983). Given Unger's basic agreement with the positions of three liberal legal theorists, he perhaps overstates the case. Indeed the goal of this Article is to question something that the critical legal theorist Unger appears to share with his liberal opponentsthe view that legal incoherence is a solely a property of a legal object, as opposed to an effect produced by the object's encounter with a particular form of legal subjectivity. See Schlag, supra note 3, at 1218.

139. See Costas DOUZinas ET AL., POSTMODERN JuRISPRUdENCE: THE LAW OF TEXTS IN THE TEXTS OF LAW 65-69 (1991). 
when we imagine it as the work of a single individual, and it is coherent to the extent that it may be compared to the beliefs of an individual. This argument assumes that individuals have coherent normative beliefs or that they may be justly criticized for lacking them. In the latter case, ought implies can: because we criticize individuals for acting arbitrarily or inconsistently, we assume that morally sensitive individuals can have coherent beliefs that they exemplify through their conduct. The morally sensitive individual, who is also the individual with coherent moral beliefs, is the model for the legal system. ${ }^{140}$

What is interesting about this equation is not the analogy between individual belief and community norms but the assumption that the beliefs of morally sensitive individuals are an appropriate standard of normative coherence. If only the law could be as coherent as we ourselves are, Dworkin seems to be saying. Of course, in real life individuals are full of conflicts in their beliefs and attitudes. They manifest all sorts of contradictions and hypocrisies, and they usually engage in all sorts of strategies, conscious or otherwise, to reduce the resulting cognitive dissonance. Dworkin would surely respond that he is comparing the law to an ideal person, yet what is striking about his metaphor is that there seems to be no one who even comes close to this ideal. To be an individual is to be the seat of countless conflicting commitments, beliefs, attitudes, impulses, and desires that must be reconciled, balanced, and on occasion repressed as best one can. The morally coherent individual to whom the law is held up is a myth, a myth that projects incoherence, conflict, tension, and hypocrisy away from ourselves and onto an object that can safely be criticized for its failure to live up to what we ourselves could never obtain.

There is special irony in Dworkin's adoption of Hercules as the infinitely wise, patient, and morally sensitive judge whose efforts make the law speak with one voice. Dworkin presumably chose Hercules because of the many labors he performed, which are akin to the labors of a judge to make the law normatively coherent. Yet in Greek mythology Herakles embarked on his labors as penance for an attack of madness in which he slaughtered his own children. ${ }^{141}$ It is therefore entirely fitting that Dworkin would choose a

140. As Dworkin puts it:

We want our neighbors to behave, in their day-to-day dealings with us, in the way we think right. But we know that people disagree to some extent about the right principles of behavior, so we distinguish that requirement from the different (and weaker) requirement that they act in important matters with integrity, that is, according to convictions that inform and shape their lives as a whole, rather than capriciously or whimsically. . . . Integrity becomes a political ideal when we make the same demand of the state or community taken to be a moral agent, when we insist that the state act on a single, coherent set of principles . ... We assume, in both the individual and the political cases, that we can recognize other people's acts as expressing a conception of faimess or justice or decency even when we do not endorse that conception ourselves.

DWORKIN, supra note 8, at 166.

141. See Robert GRAVES, 2 The GREeK Myths 100-01 (1990). 
character who lost his mind through forces beyond his control as a model for human attempts to make the law coherent by mimicking the coherence of human beliefs. Herakles is an uncannily appropriate symbol of a human consciousness that is never fully in control of itself (Herakles' madness was ordained by the gods) and that must do the best it can to make sense of its own conflicting elements and the world in which it finds itself. At the same time, Herakles is an equally apt symbol of a legal system that, like most people, must hide and suppress its many incoherences and conflicts of value and keep, as best it can, its many skeletons safely in the closet.

The unintended irony of Dworkin's literary conceit presents, in a microcosm, the ideological strategy of his jurisprudential project: to employ individual consciousness as the model of coherent normative thought, thus preserving the sanctity and coherence of the legal subject by projecting its difficulties onto the object of its seemingly disinterested contemplation. In this way, the subject of legal understanding is removed from discussion except to serve as a model of propriety against which the law will be measured. Thus, to personify law is not, as some have suggested, ${ }^{142}$ merely to disguise the incoherence of law; it is to disguise the potential incoherence of personal belief and the potential effects that the subject brings to the object of legal understanding. The personification of law is, in fact, a dual projection: it sustains the belief in our own coherence by projecting incoherence away from us so that our beliefs may serve as a standard for judging an object (the law) onto which we have already projected our own incoherences and internal conflicts.

The alternative perspective on coherence-that politics and the struggle of interest groups make legal coherence impossible-might at first seem radically different. Yet this view, no less than Dworkin's, assumes that coherence or incoherence is a property of law revealed when law is understood from a single correct standpoint. Moreover, this position, no less than Dworkin's, is premised on the insulation of the legal subject from jurisprudential scrutiny.

Viewing politics as the cause of legal incoherence involves its own form of projection. By blaming interest-group struggle for legal incoherence, we invite the possibility that but for politics, the law would be coherent. Moreover, we preserve belief in the coherence of the legal in those areas not deemed "political." Thus, Joseph Raz, after arguing that politics makes global legal coherence impossible, nevertheless suggests that we "would expect [the law] to be coherent in bits-in areas relatively unaffected by continuous political struggles-and incoherent in others."143 "Perhaps," Raz ventures, the

142. See DouzINAS ET AL., supra note 139 , at 66-72.

143. Raz, The Relevance of Coherence, supra note 13, at 295. 
law might be "coherent regarding the mental conditions of criminal liability, but not on the rights and wrongs of abortion."144

This way of thinking invokes a surprisingly simple set of structural homologies: a single mind is to a clash of wills as coherence is to incoherence, as law is to politics, as uncontroversial subjects are to controversial subjects, as consensus is to continuous political struggle, as nonpolitical parts of law are to political parts of law. Within this framework, law is coherent to the extent that it is free from politics, defined as pluralistic struggle over controversial issues like abortion. On the other hand, where issues are not controversial, where forces do not contend, the law is apolitical and can resemble the coherent beliefs we associate with a single individual.

This simple ideological framework has many far-reaching effects. It projects normative incoherence away from "uncontroversial law" and onto politics while simultaneously projecting normative coherence onto the absence of politics and what is deemed "uncontroversial law." It associates lack of consensus with politics while viewing areas of wide agreement as relatively apolitical and hence the home of coherence. It thus identifies the presence and sources of incoherence with overt political conflicts while making invisible the potential normative incoherence in what is taken for granted or consistent with widely shared cultural practices. It reinforces the appearance of the nonideological in widely shared ideologies.

Above all, this framework projects the source of incoherence outward from individual beliefs onto conflicts between individuals or groups of individuals. By identifying the source of incoherence as conflict between individuals and their respective beliefs, we make invisible the possible incoherence stemming from conflicts within each individual among her beliefs. We thus preserve the coherence of individual belief by externalizing conflict away from the inner world of the self and projecting it onto the outer world of politics.

We now see how much Raz's pessimism about legal coherence shares with Dworkin's optimism. Accepting that the law is incoherent because of external political conflict may actually serve the larger ideological goal of supporting a view that our own individual beliefs are coherent. It protects the coherence of the self's beliefs by projecting incoherence away from the self and onto the arena of political conflict.

The externalization of inner conflict onto the outside world is hardly limited to jurisprudential discussions. Indeed, many of our most common metaphors for internal conflict speak in terms of external or interpersonal conflict. ${ }^{145}$ What is most important in the jurisprudential context is that this

144. Id. I assume that Raz would count as exceptional cases in which criminal liability for abortion would turn on questions of intention (e.g., mistake of fact about the viability of the fetus) so that "political" disputes about abortion might affect the interpretation of an otherwise "uncontroversial" area of law.

145. Thus, we say that ideas are warring in our heads, as if they were separate individuals who could engage in combat. The anthropomorphism of our ideas analogizes internal conflict to external struggle 
projection insulates the subject of understanding from jurisprudential scrutiny by implicitly adopting it as the norm of coherent belief and the relevant point of comparison. Just as with Dworkin's rhetoric of personification, the beliefs of a morally sensitive individual are the model of coherence against which the incoherence produced by interpersonal political struggle may be compared. To speak this way implies that if the law were not the result of political struggle - if the law were produced by a single mind-it would be coherent because it would match the coherent beliefs of one individual. Posed against the image of warring factions writing their conflicting views into law is the image of the single lawmaker composing a coherent scheme of legal regulation. We thus discount the very real possibility that even if a single individual wrote the law by herself, it still might lack normative coherence because the source of unresolved moral tension may lie not in political struggle between individuals but in individual belief. ${ }^{146}$

In offering this analysis I am not claiming that the clash of wills in a pluralist democracy does not contribute to normative incoherence. It surely does. My point is rather that such a claim conceals as much as it illuminates. It allows us to suppress recognition of the many internal compromises individuals make that are called principled behavior. Believing that incoherence is caused by politics, or by the clash of individuals in culture, allows us to forget the clash of conflicting values and desires within that bear the name of normalcy.

Thus, blaming normative incoherence on history or political struggle makes invisible the previous results of struggle already internalized within us. Recall that the subject who understands the law is always socially constructed. Our sense of the normal, the uncontroversial, of "what goes without saying," is the result of an internalization of a culture and its norms; yet culture itself is always the product of previous clashes, conflicts, and compromises. Hence moral conflicts and tensions in our culture appear invisible to us precisely because they are the norm and exist as a norm for identifying the situations that could present an unacceptable conflict or compromise of principle. To take one example, conflicts between liberty and security or liberty and equality in American culture do not exist merely as the clash of opposed individuals or groups of individuals; they are also in the "cultural software"-the set of tools of understanding - that a culture bequeaths to the individuals who live within it. Conflicts of value may appear invisible to us to the extent that we accept

among individuals. Similarly, we speak of the demons inside us, or the conflict between our heart and our head, our reason and our appetites.

146. By identifying the causes of incoherence primarily with conflicts between individuals, we also tend to see individuals as the bearers of opposing principles (e.g., Reagan or Thatcher as standing for free markets) rather than understanding individual belief as a collection of conflicting principles that manifests itself differently in different contexts. As a result, we sometimes misunderstand individual political action, for individuals are likely to be more complicated than the political personas assigned to them would suggest. 
a culture's norms as our own. To the extent that we are aware of these conflicts, we may explain them in terms of a clash of individual wills rather than as a clash of warring values within ourselves. ${ }^{147}$

In this way history and politics can be the sources of normative incoherence, but in a much more complicated way. Moral incoherence in individual belief may result from the internalization of cultural norms that are themselves the sedimentation of different historical practices. If culture is bricolage-the catch-as-catch-can assemblage and juxtaposition of tools of understanding accumulated over history-this bricolage resides in us as well as in the culture we inhabit. To exist in history is just to internalize the untidy mélange of conflicting traditions, values, and norms that constitutes historical consciousness. Thus, history and politics can be the cause of normative incoherence if we recognize that the relics of history and previous political struggle already exist within us. On the other hand, by blaming normative incoherence on politics or history conceptualized as events external to us, we make invisible history's previous construction of our selves. We imagine ourselves to be the seat of rationality surrounded by an external world of unreason. We see history and culture without us but not within us. Once again, we imagine the self's autonomy from the forces that make the self what it is.

In this Article I have tried to recover and reconsider what traditional jurisprudence has projected from the legal subject to the legal object-to reclaim the contributions of subjectivity to the nature of the law. Ironically, perhaps the greatest obstacle to this project has been the very question that jurisprudence has traditionally posed to itself: "What is the nature of law?" or, in another form, "What properties does the legal system have?" This question, seemingly so innocent and straightforward, already disguises many of the most fundamental features of that which it seeks to understand. It simultaneously conceals the legal subject's location within a culture, her purposes in understanding, the political and moral beliefs she brings to interpretation, her psychological needs to make the law fit within her social world and her conception of self, and, above all, the cratological component of understanding-her vulnerability through interpretation and the effects that legal understanding has on her. That so much could be concealed in a basic jurisprudential question tells us as much about the ideological situation of jurisprudence as it does about the legal system. From a critical perspective jurisprudence must itself be a subject of jurisprudence; the construction of the questions that jurisprudence asks itself must also be on the table for analysis and discussion. If, as I have argued in this Article, these questions conceal as much as they reveal, if they presuppose a theory of subjectivity that is false and whose falsity is necessary to their continued centrality, we must be willing to jettison these questions and ask new ones in their stead. We can no longer

147. See Bernard Williams, MORAL LUCK 72-73 (1981). 
remain content to imagine law's nature exterior to us; we must search for the nature of the law within. 